\title{
Altered cerebellar oscillations in Parkinson's disease patients during cognitive and motor tasks
}

Taylor J. Bosch, ${ }^{1,2}$ Christopher Groth, ${ }^{3}$ Tiffany A. Eldridge, ${ }^{2}$

Etienne Z. Gnimpieba, ${ }^{1,4}$ Lee A. Baugh, ${ }^{1,2}$ Arun Singh, ${ }^{1,2, *}$

${ }^{1}$ Center for Brain and Behavior Research, University of South Dakota, Vermillion, SD, USA

${ }^{2}$ Division of Basic Biomedical Sciences, Sanford School of Medicine, University of South

Dakota, Vermillion, SD, USA

${ }^{3}$ Department of Neurology, University of Iowa, Iowa City, IA, USA

${ }^{4}$ Department of Biomedical Engineering, University of South Dakota, Vermillion, SD, USA

\section{*Correspondence to:}

Dr. Arun Singh

Division of Basic Biological Sciences,

Sanford School of Medicine,

University of South Dakota,

414 E. Clark St. Vermillion, SD, 57069, USA

Email: arun.singh@usd.edu

Running title $=$ Altered cerebellar EEG in PD

Key Words: Cerebellum; occipital; EEG; oscillations; cognition; motor task.

Declarations of interest: None.

Funding sources: This work was supported by the Division of Basic Biomedical Sciences and the

Center for Brain and Behavior Research at the University of South Dakota, Vermillion, SD, USA. 
medRxiv preprint doi: https://doi.org/10.1101/2021.08.21.21262412; this version posted August 26, 2021. The copyright holder for this preprint (which was not certified by peer review) is the author/funder, who has granted medRxiv a license to display the preprint in perpetuity.

All rights reserved. No reuse allowed without permission.

\begin{abstract}
Structural and functional abnormalities in the cerebellar region have been shown in patients with Parkinson's disease (PD). Since the cerebellar region has been associated with cognitive and lower-limb motor functions, it is imperative to study cerebellar oscillations in PD. Here, we evaluated cerebellar electroencephalography (EEG) during cognitive processing and lower-limb motor performances in PD. Cortical and cerebellar EEG were collected from 74 PD patients and 37 healthy control subjects during a 7-second interval timing task, 26 PD patients and 13 controls during a lower-limb pedaling task, and 23 PD patients during eyes-open/closed resting conditions. Analyses were focused on the mid-cerebellar Cbz electrode and further compared to the midoccipital $\mathrm{Oz}$ and mid-frontal $\mathrm{Cz}$ electrodes. Increased alpha-band power was observed during the eyes-closed resting-state condition over $\mathrm{Oz}$, but no change in alpha power was observed over $\mathrm{Cbz}$. PD patients showed higher dispersion when performing the 7-second interval timing cognitive task and executed the pedaling motor task with reduced speed compared to controls. PD patients exhibited attenuated cue-triggered theta-band power over $\mathrm{Cbz}$ during both the interval timing and pedaling motor tasks. Connectivity measures between $\mathrm{Cbz}$ and $\mathrm{Cz}$ showed theta-band differences, but only during the pedaling motor task. Cbz oscillatory activity also differed from $\mathrm{Oz}$ across multiple frequency bands in both groups during both tasks. Our cerebellar EEG data along with previous magnetoencephalography and animal model studies clearly show the alteration in the cerebellar oscillations during cognitive and motor processing in PD.
\end{abstract}


medRxiv preprint doi: https://doi.org/10.1101/2021.08.21.21262412; this version posted August 26, 2021. The copyright holder for this preprint (which was not certified by peer review) is the author/funder, who has granted medRxiv a license to display the preprint in perpetuity.

All rights reserved. No reuse allowed without permission.

\section{Introduction}

The cerebellum has been implicated in cognitive control, besides playing a pivotal role in the control and coordination of motor functions. Growing evidence has suggested structural and functional abnormalities in the cerebellum in patients with Parkinson's disease (PD) which may contribute markedly to the cognitive and motor symptoms of PD (Pedroso et al., 2013; Wu and Hallett, 2013). Recent studies have shown that the cerebellar vermis and lobule V of the cerebellar anterior lobe participate actively during a dual cognitive and motor task (Wu et al., 2013; Gao et $a l ., 2017)$ and suggests that the modulations in cerebellar nuclei can affect the integrated cognitive and motor networks in PD. Both the cerebellum and basal ganglia receive input from and send output to the cerebral cortex area, forming an integrated functional network whose reciprocal anatomical connections have been confirmed using retrograde transneuronal viral transport in monkeys (Bostan et al., 2010). These connections provide a method for abnormal signals from the basal ganglia to alter cerebellar function in PD (Bostan and Strick, 2018). Altogether, the basal ganglia, the cerebellum, and the cerebral cortex form an integrated network that can control cognitive and motor processing. However, the cerebellum is one of the least characterized and investigated brain structures in this network in PD.

Deep brain stimulation (DBS) of the basal ganglia nuclei has shown therapeutic effects in PD patients, however, the effects are mostly restricted to improved upper-limb motor performance (Pollak et al., 2002; Benabid, 2003; Sharma et al., 2020). In the advanced stage of parkinsonism, patients exhibit more debilitating lower-limb motor symptoms such as gait and balance abnormalities as well as cognitive impairment. These advanced symptoms in PD cannot be treated effectively with levodopa or high-frequency DBS approaches (Hausdorff et al., 2003; St George et al., 2010; Espay et al., 2012; Rocchi et al., 2012). Recent studies have also demonstrated the relationship between cognitive deficits and gait or lower-limb motor impairment in PD patients (Kelly et al., 2012). Therefore, it is critical to seek another therapeutic target that can be used to improve both cognitive and lower-limb motor functions in PD.

Neuroimaging and animal studies have shown contributions of cerebellar areas in cognitive and motor processing in normal and disease models (Liu et al., 2013; Wu and Hallett, 2013; Festini et al., 2015; Gao et al., 2017). However, cerebellar oscillatory activity or cerebellar electroencephalography (EEG) in humans has only been discussed in some recently published 
medRxiv preprint doi: https://doi.org/10.1101/2021.08.21.21262412; this version posted August 26, 2021. The copyright holder for this preprint (which was not certified by peer review) is the author/funder, who has granted medRxiv a license to display the preprint in perpetuity.

articles where they proposed that cerebellar oscillations can be a physiological signature and therapeutic target for disease models (Andersen et al., 2020; Pan et al., 2020).

Cerebellar EEG in humans can be problematic due to its limited spatial resolution for deep sources. However, some recently published articles have discussed the possibility of detecting cerebellar EEG in detail and proposed appropriate methods with a practical guideline to optimize the collection of cerebellar oscillations with EEG electrodes (Todd et al., 2018; Andersen et al., 2020; Samuelsson et al., 2020). In the current study, we followed all of these practical guidelines to collect signals with high signal-to-noise ratio from the mid-cerebellar vermis area by placing an EEG electrode over the posterior fossa that corresponds to medial aspects of lobules VII, VIII, and IX (Todd et al., 2018). Furthermore, we compared mid-cerebellar oscillations during an interval timing cognitive task and a lower-limb pedaling motor task between PD patients and healthy control subjects. Our experimental approach showed altered mid-cerebellar oscillations in PD, suggesting a pathophysiological phenomenon and potential therapeutic target to improve cognitive and motor function.

\section{Methods}

\section{Participants}

For all experiments, a total of 79 PD patients and 37 healthy control subjects were recruited. These patients were examined by a movement disorders physician to verify that they met the diagnostic criteria recommended by the United Kingdom PD Society Brain Bank. All PD patients and healthy control subjects provided written informed consent in accordance with the Declaration of Helsinki and the Ethics Committee on Human Research. All research protocols were approved by the University of Iowa and the University of South Dakota Human Subjects Review Boards. We performed the Montreal Cognitive Assessment (MOCA; scale from 0 to 30; lower scores are worse) to measure cognition (Nasreddine et al., 2005), and the freezing of gait questionnaire (FOGQ; scale from 0 to 24; higher scores are worse) to evaluate gait severity (Giladi et al., 2000) in PD patients.

Out of all participants, 23 PD patients for resting-state data, 74 PD patients and 37 healthy controls for the interval timing task data, and 26 PD patients and 13 healthy controls for the lowerlimb pedaling task data were included (Table 1). All participants who performed the lower-limb motor task also participated in the interval timing task. We also recruited 5 PD patients to collect 
medRxiv preprint doi: https://doi.org/10.1101/2021.08.21.21262412; this version posted August 26, 2021. The copyright holder for this preprint (which was not certified by peer review) is the author/funder, who has granted medRxiv a license to display the preprint in perpetuity.

All rights reserved. No reuse allowed without permission.

cerebellar EEG and electromyography (EMG) signals from the nearby muscles during resting and body actions. In our previous reports, all clinical details of the patients and control groups who participated in the cognitive task (Singh et al., 2021) and lower-limb pedaling motor task (Singh et al., 2020) are described and have been summarized in Table 1. All participants performed the interval timing cognitive and lower-limb pedaling motor tasks with levodopa medication. Our previous work has shown no effect of levodopa on the interval timing task and midfrontal lowfrequency oscillations (Singh et al., 2021). Also, PD patients can exhibit freezing of gait which may cause fall risk during the off medication state. Therefore, to match with real-word motor function, PD patients performed the lower-limb pedaling motor task with levodopa medication (Singh et al., 2020).

\section{Resting-state EEG and EMG signals analysis}

Resting-state EEG data were collected during eyes-open and eyes-closed conditions to compare mid-occipital $(\mathrm{Oz})$ and mid-cerebellar $(\mathrm{Cbz})$ signals in PD patients $(\mathrm{n}=23)$. Resting-state data were epoched into consecutive epochs (5 seconds). Spectral analysis was implemented on epoched and preprocessed (see preprocessing steps below) data using the "pwelch" function in MATLAB. We selected a 1 -second time window, and the number of overlapping samples was set to $50 \%$ of the window length. Since eyes-closed EEG data are associated with alpha-band (8-12 Hz) peaks in the occipital region (van Dijk et al., 2008; Wan et al., 2019) rather than the cerebellar region, we exported the amplitude of mid-occipital and mid-cerebellar alpha oscillations to study volume conduction. In addition, we performed phase analysis using wavelet method and envelope correlation analysis comparing $\mathrm{Cbz}$ and $\mathrm{Oz}$ during the eyes-open and eyes-closed conditions in the alpha-band to compare phase angle differences and correlation coefficients between both signals.

Furthermore, we recorded 180 seconds of cerebellar EEG signals from two electrodes and EMG signals from nearby muscles to compare signals in PD patients $(n=5)$ during resting-state and action conditions. EMG electrodes were placed above the semispinalis capitis muscle. Participants performed alternating upper and lower limb flexion-extension movements for 2-3 min without any cue during the action task. We constructed a bipolar cerebellar EEG signal, fitted an envelope over the rectified high-pass $(1 \mathrm{~Hz})$ filtered EMG signal, and compared the two in the time-frequency domain using the "pspectrum" function in MATLAB. Further, both signals were 
medRxiv preprint doi: https://doi.org/10.1101/2021.08.21.21262412; this version posted August 26, 2021. The copyright holder for this preprint (which was not certified by peer review) is the author/funder, who has granted medRxiv a license to display the preprint in perpetuity.

compared in different frequency bands $(5 \mathrm{~Hz}, 10 \mathrm{~Hz}, 15 \mathrm{~Hz}$, and $20 \mathrm{~Hz}$ ) via phase analysis (wavelet method), correlation coefficient (“corrcoef"), and cross-correlation ("xcorr") methods.

\section{Interval timing cognitive and lower-limb pedaling motor tasks}

For the interval timing task used to assess differences in cerebellar oscillations during a cognitive task, individuals were required to estimate the duration of either a 3- or 7- second interval. Briefly, individuals were instructed before the beginning of interval estimation whether the upcoming interval was short or long. Afterwards, a visual cue (solid box) on a computer screen was displayed for either 8-10 seconds for the short interval conditions or 18-20 seconds for the long interval conditions. Individuals were then required to indicate once they believed the target duration had been achieved by pressing the space bar on a computer. Here, we analyzed only 7-s interval timing task-related signals since no electrophysiological differences in frontal theta-band activity and less variation in response time were observed during the 3-s interval timing task in PD patients compared to controls (Singh et al., 2021). Also, in prior work, distinctions between theta-band activity were more reliable for the longer 7-second intervals than for 3-second intervals (Parker et al., 2015; Kim et al., 2017; Singh et al., 2021). There were 40 trials of the 7-second interval condition. To analyze cognitive behavior during the interval timing task, we computed the coefficient of variation of the response time (RTCV) (Singh et al., 2021).

For the lower-limb pedaling task used to assess differences in cerebellar oscillations during a motor task, a protocol previously developed to study lower-limb movement control specifically in PD patients was used (Singh et al., 2020). Briefly, individuals were seated and instructed to complete one full rotation of the pedaling device after being presented with a visual cue (green circle) 1-2 seconds after receiving a warning cue. This was completed between two separate blocks of either 30 or 50 trials per block. Similar to our prior report, we computed the linear speed for pedaling trials from the accelerometer signals (Singh et al., 2020).

\section{Cerebellar and cortical EEG signals and analysis}

In the current study, we used a customized 64-channel EEG cap with embedded active electrodes (actiCAP, EasyCap, Inc) in accordance with the extended version of the international 10/20 system. EEG signals were collected using a high pass filter of $0.1 \mathrm{~Hz}$ and a sampling rate of 500 Hz. During data collection, the Pz electrode was used as the reference electrode and the FPz 
medRxiv preprint doi: https://doi.org/10.1101/2021.08.21.21262412; this version posted August 26, 2021. The copyright holder for this preprint (which was not certified by peer review) is the author/funder, who has granted medRxiv a license to display the preprint in perpetuity.

electrode was used as the ground electrode. This EEG cap was customized to include electrodes covering the posterior fossa corresponding to the medial aspects of cerebellar lobules VII, VIII, and IX. The I1 and 2 electrodes corresponding to cerebellar $(\mathrm{Cb} 1$ and $\mathrm{Cb} 2)$ coverage replaced PO3 and PO4 in the EEG cap. Another channel was added corresponding to a central cerebellar location $(\mathrm{Cbz})$. Cerebellar electrodes were placed $1 \mathrm{~cm}$ below the occipital electrode (Edagawa and Kawasaki, 2017). The channels Fp1, Fp2, FT9, FT10, TP9, and TP10 were removed from subsequent analyses since they often correspond to eyeblink and muscle artifact.

Following data collection, data were imported into EEGLAB for preprocessing (Delorme and Makeig, 2004). For each task, bad channels were identified, removed, and interpolated. Following interpolation, data were epoched based on the task. For the interval timing task, EEG data were epoched starting two seconds before stimulus onset and ending twenty seconds after stimulus onset for the 7-second interval condition. For the lower limb pedaling task, data were epoched starting one second prior to stimulus onset and ending three seconds after stimulus onset. For both tasks, bad epochs were identified and rejected using a combination of the FASTER (Nolan et al., 2010) and ADJUST (Mognon et al., 2011) algorithms, and the "pop_rejchan" function in EEGLAB. These datasets then underwent independent component analysis and eye blink artifact was identified and removed by a trained experimenter.

Following preprocessing, time-frequency analyses were performed for all tasks using complex Morlet wavelets, as explained previously (Singh et al., 2018; Singh et al., 2019; Singh et al., 2021). Briefly, wavelets increased from $1-50 \mathrm{~Hz}$ in logarithmically spaced steps defining the cycles of each frequency band increasing from 3-10 cycles between 1-50 Hz and taking the inverse fast Fourier transform. Epochs were defined differently based on the task. For the interval timing task, epochs were defined starting 500 milliseconds prior to stimulus onset continuing to 1000 milliseconds after stimulus onset. For the lower limb pedaling task, epochs were defined starting 500 milliseconds prior to stimulus onset continuing to 2000 milliseconds after stimulus onset. Power was normalized by converting to a decibel $(\mathrm{dB})$ scale which allows direct comparisons across frequency bands. As in our previous studies, the baseline for each frequency was calculated by averaging power from $-300--200$ milliseconds prior to stimulus onset (Singh et al., 2018; Singh et al., 2019; Singh et al., 2020).

Time-frequency region of interest (tf-ROI) analyses during cognitive and motor tasks were performed primarily at the electrode of interest, $\mathrm{Cbz}$ over the mid-cerebellar (vermis) region. 
medRxiv preprint doi: https://doi.org/10.1101/2021.08.21.21262412; this version posted August 26, 2021. The copyright holder for this preprint (which was not certified by peer review) is the author/funder, who has granted medRxiv a license to display the preprint in perpetuity.

Furthermore, we analyzed a nearby mid-occipital electrode, Oz, and compared between both electrodes to rule out contamination due to volume conduction. In accordance with our previous cognitive and pedaling task-related EEG reports, tf-ROI analyses were constrained to a pre-defined theta-band (4-7 Hz) and cue-triggered 0-500 milliseconds time window (Singh et al., 2018; Singh et al., 2019; Singh et al., 2020; Singh et al., 2021). In addition to this well-motivated tf-ROI, we used a cluster size of 500 pixels and a t-test as in our past work (Singh et al., 2020; Singh et al., 2021).

Furthermore, we selected a pre-defined delta-band (1-4 Hz) and our time-window of interest was 0-500 milliseconds from the cue for both cognitive and pedaling motor tasks. We also included the beta-band $(13-30 \mathrm{~Hz})$ in the analysis but the time-window of interest for the interval timing task was 0-500 milliseconds from the response, and 500-2000 milliseconds from the cue for the pedaling motor task. We compared power values in those frequency bands to determine the difference between mid-cerebellar $\mathrm{Cbz}$ and mid-occipital $\mathrm{Oz}$ electrodes.

We also performed task-related connectivity analyses to observe the oscillatory relationship between the mid-frontal and mid-cerebellar regions. Since our previous reports have shown abnormal midfrontal activity in the theta-band at the time of the cue during both interval timing cognitive and lower-limb pedaling motor tasks in PD patients (Singh et al., 2020; Singh et al., 2021), this analysis may shed light on the role of the cortico-cerebellar network in cognitive processing and lower-extremity movements in PD patients. We applied phase and power-based connectivity analysis methods to measure spectral coherence and power correlation between signals collected from $\mathrm{Cbz}$ and $\mathrm{Cz}$ electrodes during the interval timing cognitive and lower-limb pedaling motor tasks (Cohen, 2014).

\section{Statistical analysis}

For the initial resting-state EEG analysis comparing mid-occipital electrode $\mathrm{Oz}$ to mid-cerebellar electrode $\mathrm{Cbz}$, a $2 \times 2$ repeated measures analysis of variance (rmANOVA) was performed with condition (eyes-open and eyes-closed) and electrode (Oz and $\mathrm{Cbz}$ ) as primary factors for alpha oscillations. Independent t-tests were performed to assess the difference between PD patients and healthy control subjects for the interval timing and lower-limb pedaling tasks. We also used Pearson correlation analyses to evaluate the relationship between theta and beta power values during the interval timing task and cognitive measurements (MOCA scores); and between theta 
medRxiv preprint doi: https://doi.org/10.1101/2021.08.21.21262412; this version posted August 26, 2021. The copyright holder for this preprint (which was not certified by peer review) is the author/funder, who has granted medRxiv a license to display the preprint in perpetuity.

All rights reserved. No reuse allowed without permission.

and beta power values during the lower-limb pedaling motor task and gait severity measurements (FOG scores) of PD patients. Moreover, we performed an rmANOVA including electrodes (midcerebellar $\mathrm{Cbz}$ and mid-occipital $\mathrm{Oz}$ ) as a within-subjects variable and group as a between-subjects variable (PD and controls). An alpha level of $<0.05$ was adjusted for multiple comparisons via the Bonferroni correction method, where appropriate. The horizontal lines and white circles in the violin plots represent the mean and median values, respectively.

\section{Results}

\section{Feasibility of cerebellar EEG}

Initially, we explored whether cerebellar EEG is a feasible method for indirectly assessing cerebellar activation in human subjects. Due to volume conduction and the proximity to occipital electrodes, it was important to distinguish between $\mathrm{Cbz}$ and $\mathrm{Oz}$ during resting-state EEG in PD patients (Fig. 1). The results of the $2 \times 2$ rmANOVA examining effects of electrode and restingstate condition in the alpha-band revealed a main effect of electrode $\left(F_{1,22}=6.56, p=0.018\right)$, a main effect of resting-state condition $\left(\mathrm{F}_{1,22}=8.56, \mathrm{p}=0.008\right)$, and an interaction between these factors $\left(\mathrm{F}_{1,22}=4.85, \mathrm{p}=0.038\right)$. Subsequent pairwise comparisons demonstrated a significant difference between eyes-closed and eyes-open conditions in the mid-occipital Oz electrode $(\mathrm{p}=$ 0.012). Similar to previous studies, our mid-occipital EEG signal showed a regional peak in the alpha-band during the eyes-closed condition (mean $\pm \mathrm{sem}=4.14 \pm 1.1 \mu \mathrm{V}^{2}$; Fig. 1) compared to the eyes-open condition (1.65 $\pm 0.37 \mu \mathrm{V}^{2}$; Fig. 1) (van Dijk et al., 2008; Wan et al., 2019). Further, alpha-band mid-cerebellar Cbz oscillations showed lower power $\left(2.39 \pm 0.48 \mu \mathrm{V}^{2}\right.$; Fig. 1) and were significantly different from mid-occipital Oz alpha oscillations $(\mathrm{p}=0.02)$ during the eyesclosed condition, thus showing an absence of volume conduction from alpha oscillations generated in the occipital region. No difference between $\mathrm{Oz}$ and $\mathrm{Cbz}$ alpha-band power during the eyes-open condition was observed $(\mathrm{p}=0.2)$. In addition, phase and envelop correlation analyses comparing $\mathrm{Cbz}$ and $\mathrm{Oz}$ during the eyes-open and eyes-closed conditions in the alpha-band showed greater and dispersed phase angle differences as well as lower and distributed envelop correlation coefficients during the eyes-closed condition (Fig. S1).

Moreover, signals recorded from the cerebellar EEG electrodes and nearby EMG leads during the rest and action conditions showed differences after applying 1-50 Hz band-pass filters (Fig. S2A). When enveloped signals were compared between EEG and EMG electrodes at 
medRxiv preprint doi: https://doi.org/10.1101/2021.08.21.21262412; this version posted August 26, 2021. The copyright holder for this preprint (which was not certified by peer review) is the author/funder, who has granted medRxiv a license to display the preprint in perpetuity.

different frequency bands $(5,10,15,20 \mathrm{~Hz})$, phase analysis showed normally distributed phase differences (Fig. S2B), correlation coefficients were minimal between (Fig. S2C), and crosscorrelation analyses showed minimal zero-lag relationships between both signals (Fig. S2D). Though activity can be seen around $5 \mathrm{~Hz}$ and its higher harmonics in these analyses between EEG and EMG signal, they were thoroughly preprocessed and removed in the resting-state, cognitive, and motor tasks. Altogether, both our resting-state eyes-open and eyes-closed data showed the feasibility of cerebellar EEG signals and revoked the probability of volume condition from the nearby occipital electrode. Also, cerebellar EEG and EMG signals showed that in our setup, muscle activity close to cerebellar electrodes did not contaminate the cerebellar EEG signals during the task conditions.

\section{Cerebellar EEG in PD patients during a cognitive task}

Following the initial comparisons between $\mathrm{Oz}$ and $\mathrm{Cbz}$ oscillatory activities during resting state, we explored whether there were differences in mid-cerebellar EEG activity between PD and healthy control subjects during 7-second interval timing cognitive processing (Fig. 2A). Our recently published study on the same dataset demonstrated higher RTCV in PD patients compared to controls (RTCV: controls $=0.15 \pm 0.01, \mathrm{PD}$ patients $=0.24 \pm 0.02 ; \mathrm{t}_{109}=-3.31, \mathrm{p}=0.001$ ). Behavior response outcomes clearly demonstrated cognitive deficits in our patients compared to controls. Electrophysiological activity in the mid-cerebellar region during the 7-s interval timing task showed significantly reduced cue-triggered theta-band power in PD patients compared to healthy controls (mean \pm sem: controls $=1.15 \pm 0.26 \mathrm{~dB}$, PD patients $=-0.01 \pm 0.17 \mathrm{~dB} ; \mathrm{t}_{109}=$ 3.75, $\mathrm{p}=0.0003$; Fig. 2A-C). Interestingly, we found that cue-triggered mid-cerebellar theta activity in the interval timing task correlated with cognitive impairment in $\mathrm{PD}(\mathrm{r}=0.28, \mathrm{p}=0.017$; Fig. 2D) and a trend was observed between theta activity and RTCV $(r=-0.22, p=0.06)$. In addition, beta-band power in PD patients was higher compared to healthy controls (controls $=-1.18 \pm 0.09$ $\mathrm{dB}, \mathrm{PD}$ patients $=-0.89 \pm 0.06 \mathrm{~dB} ; \mathrm{t}_{109}=-2.52, \mathrm{p}=0.01$; Fig. S3 A and B) and we did not find a significant correlation between beta power and MOCA scores or RTCV (Fig. S3 C and D).

We further compared the difference between mid-cerebellar Cbz activity and mid-occipital Oz activity during the 7-second interval timing cognitive task (Fig. S4) in delta, theta, and beta frequency bands in PD patients and controls. Cue-triggered delta and theta power were significantly attenuated in the mid-cerebellar $\mathrm{Cbz}$ region compared to the mid-occipital Oz region 
medRxiv preprint doi: https://doi.org/10.1101/2021.08.21.21262412; this version posted August 26, 2021. The copyright holder for this preprint (which was not certified by peer review) is the author/funder, who has granted medRxiv a license to display the preprint in perpetuity. All rights reserved. No reuse allowed without permission.

in PD patients (Fig. S4 and Table S1). Furthermore, response-related beta power was significantly reduced in PD patients compared to controls during the interval timing task and a trend towards a reduction in beta power was also found in the mid-cerebellar Cbz region compared to the midoccipital Oz region in PD patients (Fig. S4 and Table S1).

Finally, we explored the connection between mid-frontal and mid-cerebellar regions. Both spectral coherence and power correlation analyses showed no significant differences in connectivity at the cue-triggered theta-band during the interval timing task (Fig. S5).

\section{Cerebellar EEG in PD patients during a lower-limb pedaling motor task}

Finally, we explored whether there are differences in mid-cerebellar Cbz activity between PD patients and healthy control subjects during lower-limb pedaling motor performance (Fig. 3A). Our prior study on the same dataset showed that PD patients performed the pedaling motor task with reduced speed compared to controls (speed: controls $=0.016 \pm 0.002 \mathrm{~m} / \mathrm{s}, \mathrm{PD}$ patients $=0.008$ $\left.\pm 0.001 \mathrm{~m} / \mathrm{s} ; \mathrm{t}_{37}=4.2, \mathrm{p}=0.0002\right)($ Singh et al., 2020). Mid-cerebellar EEG activity during the lower-limb pedaling motor task showed significantly reduced cue-triggered theta-band power in PD patients compared to healthy controls (mean \pm sem: controls $=3.3 \pm 0.67 \mathrm{~dB}, \mathrm{PD}$ patients $=$ $0.62 \pm 0.27 \mathrm{~dB} ; \mathrm{t}_{37}=4.45, \mathrm{p}=0.0001$; Fig. $\left.3 \mathrm{~A}-\mathrm{C}\right)$. Similarly, our prior study demonstrated a reduction in cue-triggered mid-frontal theta power in PD patients due to participants performing the pedaling motor task after seeing the imperative stimulus, which required attention or cognitive load (Singh et al., 2020). Strikingly, we found that cue-triggered mid-cerebellar theta activity in the lower-limb pedaling motor task correlated with gait impairment in PD ( $r=-0.53, p=0.006$; Fig. 3D). In addition, we compared cue-triggered beta-band power in PD patients to healthy controls but found no significant difference between groups, although the beta power was higher in the mid-cerebellar electrode in PD (mean \pm sem: controls $=-0.04 \pm 0.2 \mathrm{~dB}, \mathrm{PD}$ patients $=0.3 \pm 0.2$ $\mathrm{dB} ; \mathrm{t}_{37}=-1.12, \mathrm{p}=0.27$; Fig. $3 \mathrm{E}-\mathrm{F}$ ). We also noticed no association between mid-cerebellar betaband power and gait impairment in $\mathrm{PD}(\mathrm{r}=0.13, \mathrm{p}=0.534$; Fig. 3G), suggesting that changes in the beta-band during movement and the relationship between beta power and motor symptoms in PD may be limited to motor cortical, frontal, and subcortical regions (Singh et al., 2013; Singh, 2018; Singh et al., 2020).

Subsequently, we compared the difference between mid-cerebellar Cbz activity and midoccipital $\mathrm{Oz}$ activity during the lower-limb pedaling motor task (Fig. S6) in delta, theta, and beta 
medRxiv preprint doi: https://doi.org/10.1101/2021.08.21.21262412; this version posted August 26, 2021. The copyright holder for this preprint (which was not certified by peer review) is the author/funder, who has granted medRxiv a license to display the preprint in perpetuity.

All rights reserved. No reuse allowed without permission.

frequency bands in PD patients and controls. Cue-triggered delta and theta power values were significantly attenuated in both $\mathrm{Cbz}$ and $\mathrm{Oz}$ regions of PD patients compared to controls (Fig. S6 and Table S1). However, movement-related mid-cerebellar $\mathrm{Cbz}$ beta power was significantly elevated in PD patients compared to the mid-occipital Oz region (Fig. S6 and Table S1).

Furthermore, spectral coherence and power correlation analyses showed significant differences in connectivity at the theta-band during the lower-limb pedaling motor task (Fig. S7). Additionally, since a previous study suggested a higher expected signal from lateral cerebellar regions (Samuelsson et al., 2020), we further analyzed left cerebellar Cb1 and right cerebellar Cb2 signals during the interval timing cognitive and lower-limb pedaling motor tasks. Our results showed similar oscillatory changes between PD and controls in both lateral cerebellar EEG signals and mid-cerebellar EEG during both the interval timing cognitive (Fig. S8) and lower-limb pedaling motor tasks (Fig. S9). Furthermore, rmANOVAs revealed a significant main effect of electrode when comparing $\mathrm{Cb} 1, \mathrm{Cbz}$, and $\mathrm{Cb} 2$ in the theta-band for both tasks. Table S2 and Table $\mathrm{S} 3$ show the mean values and rmANOVA results, respectively. These results suggest that there are differences across cerebellar electrodes in the theta-band, but differences between PD patients and controls persist across cerebellar electrodes.

\section{Discussion}

The purpose of the following study was three-fold. First, we sought to demonstrate the viability of cerebellar EEG measurements via appropriate methods and experimental setup (Edagawa and Kawasaki, 2017; Pan et al., 2020; Samuelsson et al., 2020). Second and third, we aimed to characterize the EEG signature of cerebellar abnormalities in PD in the cognitive domain using an interval timing task (second), as well as in the motor domain using a lower-limb pedaling motor task (third). Our results demonstrate the viability of cerebellar EEG and characterize theta-band PD abnormalities in the cognitive domain and motor domain at the time of attention or cognitive load.

Since there is a well-documented alpha oscillation in the occipital region during restingstate eyes-closed conditions (van Dijk et al., 2008; Wan et al., 2019), we also confirmed the presence of a mid-occipital alpha peak in our patients during the eyes-closed condition only. However, this peak was absent over the mid-cerebellar electrode, suggesting that mid-cerebellar EEG was not affected by occipital EEG due to volume conduction. In our study, the eyes-closed 
medRxiv preprint doi: https://doi.org/10.1101/2021.08.21.21262412; this version posted August 26, 2021. The copyright holder for this preprint (which was not certified by peer review) is the author/funder, who has granted medRxiv a license to display the preprint in perpetuity. All rights reserved. No reuse allowed without permission.

related occipital alpha peak in PD patients was also unaffected by age and disease, since the alpha peak has been seen in older healthy people in resting-state eyes-closed conditions (Barry and De Blasio, 2017). Overall, our data demonstrates that the signal measured from the mid-cerebellar electrode functionally differs from the signal measured from the mid-occipital electrode.

Our interval timing task-related results provide insight into the role of cerebellar oscillations in the nature of temporal cognitive dysfunction in PD patients. First, the cerebellar network has been shown to support resonance within the low-frequency theta-band (D'Angelo et al., 2001; Dugue et al., 2009). Moreover, there is evidence in animal models that these lowfrequency oscillations synchronize within cerebellar hemispheres as well as between cerebellar and cortical regions (Hartmann and Bower, 1998; O'Connor et al., 2002). Previous studies have suggested a relationship between cognitive processing and frontal low-frequency oscillatory activity (Cavanagh and Frank, 2014; Singh et al., 2018) as well as cerebellar activity (Wu et al., 2013; Gao et al., 2017). It should be noted that our prior report on the same patients has shown attenuated frontal theta activity during the interval timing task, thus suggesting the presence of altered theta oscillations in the frontal-cerebellar network (Singh et al., 2021). Studies on cerebellar theta oscillations indicate that our method may be engaging resonant frequencies in cerebellar networks that favor cognitive processing. Moreover, neuromodulation in the cerebellar region can increase theta activity and thus improve cognitive functions (Schutter and van Honk, 2006; Singh et al., 2019), possibly by inducing long-lasting changes in the interconnected corticocerebellar networks in the disease condition (Chen and Desmond, 2005; Koch, 2010; Brissenden et al., 2018).

Low-frequency theta oscillations can engage not only cortical and cerebellar regions, but also basal ganglia regions such as the subthalamic nucleus as well as other brain areas (Herz et al., 2016; Kelley et al., 2018). The substantial disynaptic projection between the subthalamic nucleus and cerebellar cortex forms an integrated functional network and provides a method for communication (Bostan et al., 2010). Our data suggest that in cognitively impaired PD patients, theta power is decreased, resulting in a failure to engage in temporal processing by the corticobasal ganglia-cerebellar networks (Milardi et al., 2019). Our findings in PD patients and controls extend this by showing cue-triggered mid-cerebellar theta oscillations that are accompanied by cognitive engagement and coordinated with frontal cortical and basal ganglia theta rhythms. Interestingly, spectral coherence and power correlations between mid-frontal and mid-cerebellar 
medRxiv preprint doi: https://doi.org/10.1101/2021.08.21.21262412; this version posted August 26, 2021. The copyright holder for this preprint (which was not certified by peer review) is the author/funder, who has granted medRxiv a license to display the preprint in perpetuity. All rights reserved. No reuse allowed without permission.

regions in the theta-band during cognitive processing showed no differences between PD patients and healthy controls, suggesting that theta differences at frontal and cerebellar sites may be driven by similar, yet distinct underlying mechanisms.

Besides frontal low-frequency oscillations, beta oscillations have also been shown to be associated with the time of execution in cognitive tasks (Stoll et al., 2016) and linked to top-down behavioral control (Buschman and Miller, 2007). Intracranial and scalp EEG recordings in humans have shown changes in the beta-band power within the frontal cortex and subthalamic nucleus when responding during a cognitive processing task, which can be related to the motor component of cognitive task performance (Aron et al., 2007; Swann et al., 2011). This suggests that the betaband could also be important for communication in the frontal-basal ganglia circuit during cognitive-motor processing. These oscillations could represent the interaction between the frontalbasal ganglia network and the cerebellar region, as shown by the beta activity at the time of response or keypress in our interval timing task data.

Besides in high-level cognitive processes, the cerebellum also plays a fundamental role in controlling and executing voluntary movement. The cerebellum's primary motor role is to modulate frontal cortical and motor cortical regions through cerebello-thalamo-cortical connections (Strick, 1985). Our prior report has demonstrated a reduction in cue-triggered frontal theta activity during the lower-limb pedaling motor task in PD patients compared to controls (Singh et al., 2020). Of note, our current results in the same patients show a reduction in cuetriggered mid-cerebellar theta activity during the pedaling task in PD patients. As discussed above, the entrainment of cue-triggered theta oscillations occurs from frontal to cerebellar regions via cortico-cerebellar circuitry, specifically when one plans to execute a motor task that requires cognitive engagement. Though changes in cerebellar activity can directly affect motor control, changes in attentional and executive functions can result in slowness during lower-limb motor performance in PD. As such, attentional and other cognitive training methods have been used as an intervention to improve lower-limb movements in PD (Walton et al., 2018). Cerebellar recordings in animal models support our motor-task-related results by showing changes in theta activity during movements (O'Connor et al., 2002; Courtemanche et al., 2013). Indeed, entrainment of theta oscillations in the cerebellar region via theta frequency stimulation has shown improvement in visuo-motor tasks by modulating neural activity in focal and interconnected motor networks (Koch et al., 2020). This ability of the cerebellar region to generate theta oscillations 
medRxiv preprint doi: https://doi.org/10.1101/2021.08.21.21262412; this version posted August 26, 2021. The copyright holder for this preprint (which was not certified by peer review) is the author/funder, who has granted medRxiv a license to display the preprint in perpetuity. All rights reserved. No reuse allowed without permission.

during lower-limb movements, similar to the frontal region (Singh et al., 2020), suggests that these rhythms may represent a common spatiotemporal code for the fronto-cerebellar dialog. Indeed, our connectivity analyses between mid-frontal and mid-cerebellar regions in the theta band showed diminished spectral coherence and power correlations in PD patients compared to healthy controls. Our prior and current results propose that changes in theta activity across the fronto-cerebellar network may underlie deficits in lower-limb motor performance in PD patients.

Similar to our cerebellar EEG results, cerebellar MEG data in humans and cerebellar field potentials in monkeys have demonstrated modulation of beta oscillations during motor performance (Courtemanche et al., 2002; Herrojo Ruiz et al., 2017). Evidence has shown a relationship between desynchronized motor cortical beta activity and improved motor performance in PD (de Hemptinne et al., 2015; Singh, 2018). In addition, increased cortical and basal ganglia beta oscillations are associated with decreased movement in PD patients (Singh and Botzel, 2013; Singh et al., 2013; Toledo et al., 2014; Singh, 2018). Also, increased beta activity in the cerebellar region shows that synchronized beta activity in the cortico-basal ganglia-cerebellar network promotes tonic activity that can diminish lower-limb motor performance. In turn, this implicates abnormal beta oscillations in lower-limb motor dysfunction. However, our results showed no difference in beta activity between PD patients and healthy control subjects, suggesting that abnormal beta oscillations in lower-limb motor dysfunction may not manifest in cerebellar EEG. These results were further supported by our connectivity analyses between mid-frontal and midcerebellar regions in the beta band showing no differences in spectral coherence or power correlations between PD patients and healthy control subjects.

Potential limitations of the interval timing cognitive task, lower-limb pedaling motor task, and both tasks-related cortical EEG have been discussed extensively in our prior reports (Singh et al., 2020; Singh et al., 2021) since cortical and cerebellar EEG data were collected from the same participants and under similar conditions. In addition, there were several limitations to this study. EEG has low spatial resolution, so the detailed location of the cerebellum and occipital regions within the brain could not be identified. However, we confirmed that signals collected from the cerebellar electrode were different from the occipital electrode. In addition, our connectivity analyses distinguished between mid-cerebellar and mid-frontal theta oscillations in PD during our cognitive task. Future research would benefit from further examining the different contributors to cerebellar theta oscillations during cognitive processing compared to lower-limb motor 
medRxiv preprint doi: https://doi.org/10.1101/2021.08.21.21262412; this version posted August 26, 2021. The copyright holder for this preprint (which was not certified by peer review) is the author/funder, who has granted medRxiv a license to display the preprint in perpetuity.

All rights reserved. No reuse allowed without permission.

processing, as our data showed abnormal cortico-cerebellar connectivity during the lower-limb motor task, but not the cognitive task. Furthermore, we are exploring intracranial cerebellar recordings in animal models and applying combined fMRI-EEG experiments to further elucidate the cerebellar basis of oscillatory abnormalities in PD during cognitive and motor processing.

Finally, given the proximity of mid-cerebellar electrodes to the cervical neck muscles, it could be argued that the differences observed in our study could be contaminated by these muscles. However, our data were visually inspected, and all practical guidelines previously outlined were followed to ensure high signal to noise ratio from our recording electrodes and all potential musclerelated artifacts were attenuated during the preprocessing steps (Todd et al., 2018; Andersen et al., 2020; Samuelsson et al., 2020). Furthermore, the differences observed in the theta-band, but not the beta-band, suggests that general EMG contamination did not affect our results since theta differences were examined prior to movement onset. Nonetheless, future research would benefit from simultaneously recording EMG data from nearby muscles with MEG or fMRI methods during cognitive and motor tasks to definitively rule out their influence.

\section{Acknowledgments}

We would like to thank Arturo Espinoza from the University of Iowa for his help in the data collection. TJB, TAE, and AS are supported by the Division of Basic Biomedical Sciences and Center for Brain and Behavior Research at the University of South Dakota, Vermillion, SD, USA.

\section{Author Contributions}

Study design and concept: C.G., E.G.Z., L.A.B., A.S.; data collection: T.J.B., T.A.E.; A.S.; data analysis: T.J.B, E.G.Z., A.S.; drafting and revision of the manuscript: T.J.B., C.G., T.A.E., E.G.Z., L.A.B., A.S.

\section{Data Availability}

All the raw data related to the interval timing task and lower-limb pedaling motor task can be found at PRED+CT (predict.cs.unm.edu). In addition, all the postprocessed data that support the findings, and matlab codes to generate figures are available upon reasonable request from corresponding author. 


\section{Supplementary Data}

Additional supplementary information can be found in the online version of this article at the publisher's website.

\section{References}

Andersen LM, Jerbi K, Dalal SS. Can EEG and MEG detect signals from the human cerebellum? NeuroImage 2020; 215: 116817.

Aron AR, Durston S, Eagle DM, Logan GD, Stinear CM, Stuphorn V. Converging evidence for a fronto-basal-ganglia network for inhibitory control of action and cognition. J Neurosci 2007; 27: 11860-4.

Barry RJ, De Blasio FM. EEG differences between eyes-closed and eyes-open resting remain in healthy ageing. Biol Psychol 2017; 129: 293-304.

Benabid AL. Deep brain stimulation for Parkinson's disease. Curr Opin Neurobiol 2003; 13: 696706.

Bostan AC, Dum RP, Strick PL. The basal ganglia communicate with the cerebellum. Proc Natl Acad Sci U S A 2010; 107: 8452-6.

Bostan AC, Strick PL. The basal ganglia and the cerebellum: nodes in an integrated network. Nat Rev Neurosci 2018; 19: 338-50.

Brissenden JA, Tobyne SM, Osher DE, Levin EJ, Halko MA, Somers DC. Topographic Corticocerebellar Networks Revealed by Visual Attention and Working Memory. Curr Biol 2018; 28: 3364-72 e5.

Buschman TJ, Miller EK. Top-down versus bottom-up control of attention in the prefrontal and posterior parietal cortices. Science 2007; 315: 1860-2.

Cavanagh JF, Frank MJ. Frontal theta as a mechanism for cognitive control. Trends Cogn Sci 2014; 18: 414-21.

Chen SH, Desmond JE. Cerebrocerebellar networks during articulatory rehearsal and verbal working memory tasks. NeuroImage 2005; 24: 332-8.

Cohen MX. Analyzing neural time series data: theory and practice: MIT press, 2014.

Courtemanche R, Pellerin JP, Lamarre Y. Local field potential oscillations in primate cerebellar cortex: modulation during active and passive expectancy. J Neurophysiol 2002; 88: 771-82.

Courtemanche R, Robinson JC, Aponte DI. Linking oscillations in cerebellar circuits. Front Neural Circuits 2013; 7: 125.

D'Angelo E, Nieus T, Maffei A, Armano S, Rossi P, Taglietti V, et al. Theta-frequency bursting and resonance in cerebellar granule cells: experimental evidence and modeling of a slow $\mathrm{k}+-$ dependent mechanism. J Neurosci 2001; 21: 759-70.

de Hemptinne C, Swann NC, Ostrem JL, Ryapolova-Webb ES, San Luciano M, Galifianakis NB, et al. Therapeutic deep brain stimulation reduces cortical phase-amplitude coupling in Parkinson's disease. Nat Neurosci 2015; 18: 779-86.

Delorme A, Makeig S. EEGLAB: an open source toolbox for analysis of single-trial EEG dynamics including independent component analysis. J Neurosci Methods 2004; 134: 9-21. 
medRxiv preprint doi: https://doi.org/10.1101/2021.08.21.21262412; this version posted August 26, 2021. The copyright holder for this preprint (which was not certified by peer review) is the author/funder, who has granted medRxiv a license to display the preprint in perpetuity. All rights reserved. No reuse allowed without permission.

Dugue GP, Brunel N, Hakim V, Schwartz E, Chat M, Levesque M, et al. Electrical coupling mediates tunable low-frequency oscillations and resonance in the cerebellar Golgi cell network. Neuron 2009; 61: 126-39.

Edagawa K, Kawasaki M. Beta phase synchronization in the frontal-temporal-cerebellar network during auditory-to-motor rhythm learning. Sci Rep 2017; 7: 42721.

Espay AJ, Fasano A, van Nuenen BF, Payne MM, Snijders AH, Bloem BR. "On" state freezing of gait in Parkinson disease: a paradoxical levodopa-induced complication. Neurology 2012; 78: 4547.

Festini SB, Bernard JA, Kwak Y, Peltier S, Bohnen NI, Muller ML, et al. Altered cerebellar connectivity in Parkinson's patients ON and OFF L-DOPA medication. Front Hum Neurosci 2015; 9: 214.

Gao L, Zhang J, Hou Y, Hallett M, Chan P, Wu T. The cerebellum in dual-task performance in Parkinson's disease. Sci Rep 2017; 7: 45662.

Giladi N, Shabtai H, Simon ES, Biran S, Tal J, Korczyn AD. Construction of freezing of gait questionnaire for patients with Parkinsonism. Parkinsonism Relat Disord 2000; 6: 165-70.

Hartmann MJ, Bower JM. Oscillatory activity in the cerebellar hemispheres of unrestrained rats. J Neurophysiol 1998; 80: 1598-604.

Hausdorff JM, Balash J, Giladi N. Effects of cognitive challenge on gait variability in patients with Parkinson's disease. J Geriatr Psychiatry Neurol 2003; 16: 53-8.

Herrojo Ruiz M, Maess B, Altenmuller E, Curio G, Nikulin VV. Cingulate and cerebellar beta oscillations are engaged in the acquisition of auditory-motor sequences. Hum Brain Mapp 2017; 38: 5161-79.

Herz DM, Zavala BA, Bogacz R, Brown P. Neural Correlates of Decision Thresholds in the Human Subthalamic Nucleus. Curr Biol 2016; 26: 916-20.

Kelley R, Flouty O, Emmons EB, Kim Y, Kingyon J, Wessel JR, et al. A human prefrontalsubthalamic circuit for cognitive control. Brain 2018; 141: 205-16.

Kelly VE, Eusterbrock AJ, Shumway-Cook A. A review of dual-task walking deficits in people with Parkinson's disease: motor and cognitive contributions, mechanisms, and clinical implications. Parkinsons Dis 2012; 2012: 918719.

Kim YC, Han SW, Alberico SL, Ruggiero RN, De Corte B, Chen KH, et al. Optogenetic Stimulation of Frontal D1 Neurons Compensates for Impaired Temporal Control of Action in Dopamine-Depleted Mice. Curr Biol 2017; 27: 39-47.

Koch G. Repetitive transcranial magnetic stimulation: a tool for human cerebellar plasticity. Funct Neurol 2010; 25: 159-63.

Koch G, Esposito R, Motta C, Casula EP, Di Lorenzo F, Bonni S, et al. Improving visuo-motor learning with cerebellar theta burst stimulation: Behavioral and neurophysiological evidence. NeuroImage 2020; 208: 116424.

Liu H, Edmiston EK, Fan G, Xu K, Zhao B, Shang X, et al. Altered resting-state functional connectivity of the dentate nucleus in Parkinson's disease. Psychiatry Res 2013; 211: 64-71.

Milardi D, Quartarone A, Bramanti A, Anastasi G, Bertino S, Basile GA, et al. The Cortico-Basal Ganglia-Cerebellar Network: Past, Present and Future Perspectives. Front Syst Neurosci 2019; 13: 61.

Mognon A, Jovicich J, Bruzzone L, Buiatti M. ADJUST: An automatic EEG artifact detector based on the joint use of spatial and temporal features. Psychophysiology 2011; 48: 229-40. 
medRxiv preprint doi: https://doi.org/10.1101/2021.08.21.21262412; this version posted August 26, 2021. The copyright holder for this preprint (which was not certified by peer review) is the author/funder, who has granted medRxiv a license to display the preprint in perpetuity. All rights reserved. No reuse allowed without permission.

Nasreddine ZS, Phillips NA, Bedirian V, Charbonneau S, Whitehead V, Collin I, et al. The Montreal Cognitive Assessment, MoCA: a brief screening tool for mild cognitive impairment. J Am Geriatr Soc 2005; 53: 695-9.

Nolan H, Whelan R, Reilly RB. FASTER: Fully Automated Statistical Thresholding for EEG artifact Rejection. J Neurosci Methods 2010; 192: 152-62.

O'Connor SM, Berg RW, Kleinfeld D. Coherent electrical activity between vibrissa sensory areas of cerebellum and neocortex is enhanced during free whisking. J Neurophysiol 2002; 87: 2137-48. Pan MK, Li YS, Wong SB, Ni CL, Wang YM, Liu WC, et al. Cerebellar oscillations driven by synaptic pruning deficits of cerebellar climbing fibers contribute to tremor pathophysiology. Sci Transl Med 2020; 12.

Parker KL, Chen KH, Kingyon JR, Cavanagh JF, Narayanan NS. Medial frontal approximately 4$\mathrm{Hz}$ activity in humans and rodents is attenuated in PD patients and in rodents with cortical dopamine depletion. J Neurophysiol 2015; 114: 1310-20.

Pedroso JL, Braga-Neto P, de Souza PV, Barsottini OG. The cerebellum in Parkinson's disease and Parkinsonism in cerebellar disorders. Brain 2013; 136: e248.

Pollak P, Fraix V, Krack P, Moro E, Mendes A, Chabardes S, et al. Treatment results: Parkinson's disease. Mov Disord 2002; 17 Suppl 3: S75-83.

Rocchi L, Carlson-Kuhta P, Chiari L, Burchiel KJ, Hogarth P, Horak FB. Effects of deep brain stimulation in the subthalamic nucleus or globus pallidus internus on step initiation in Parkinson disease: laboratory investigation. J Neurosurg 2012; 117: 1141-9.

Samuelsson JG, Sundaram P, Khan S, Sereno MI, Hamalainen MS. Detectability of cerebellar activity with magnetoencephalography and electroencephalography. Hum Brain Mapp 2020; 41: 2357-72.

Schutter DJL, van Honk J. An electrophysiological link between the cerebellum, cognition and emotion: Frontal theta EEG activity to single-pulse cerebellar TMS. NeuroImage 2006; 33: $1227-$ 31.

Sharma VD, Patel M, Miocinovic S. Surgical Treatment of Parkinson's Disease: Devices and Lesion Approaches. Neurotherapeutics 2020; 17: 1525-38.

Singh A. Oscillatory activity in the cortico-basal ganglia-thalamic neural circuits in Parkinson's disease. Eur J Neurosci 2018; 48: 2869-78.

Singh A, Botzel K. Globus pallidus internus oscillatory activity is related to movement speed. Eur J Neurosci 2013; 38: 3644-9.

Singh A, Cole RC, Espinoza AI, Brown D, Cavanagh JF, Narayanan NS. Frontal theta and beta oscillations during lower-limb movement in Parkinson's disease. Clin Neurophysiol 2020; 131: 694-702.

Singh A, Cole RC, Espinoza AI, Evans A, Cao S, Cavanagh JF, et al. Timing variability and midfrontal $4 \mathrm{~Hz}$ rhythms correlate with cognition in Parkinson's disease. npj Parkinson's Disease 2021; 7: 1-8.

Singh A, Plate A, Kammermeier S, Mehrkens JH, Ilmberger J, Bötzel K. Freezing of gait-related oscillatory activity in the human subthalamic nucleus. Basal Ganglia 2013; 3: 25-32.

Singh A, Richardson SP, Narayanan N, Cavanagh JF. Mid-frontal theta activity is diminished during cognitive control in Parkinson's disease. Neuropsychologia 2018; 117: 113-22.

Singh A, Trapp NT, De Corte B, Cao S, Kingyon J, Boes AD, et al. Cerebellar Theta Frequency Transcranial Pulsed Stimulation Increases Frontal Theta Oscillations in Patients with Schizophrenia. Cerebellum 2019; 18: 489-99. 
medRxiv preprint doi: https://doi.org/10.1101/2021.08.21.21262412; this version posted August 26, 2021. The copyright holder for this preprint (which was not certified by peer review) is the author/funder, who has granted medRxiv a license to display the preprint in perpetuity.

All rights reserved. No reuse allowed without permission.

St George RJ, Nutt JG, Burchiel KJ, Horak FB. A meta-regression of the long-term effects of deep brain stimulation on balance and gait in PD. Neurology 2010; 75: 1292-9.

Stoll FM, Wilson CRE, Faraut MCM, Vezoli J, Knoblauch K, Procyk E. The Effects of Cognitive Control and Time on Frontal Beta Oscillations. Cereb Cortex 2016; 26: 1715-32.

Strick PL. The cerebellum: the cerebellum and neural control. Science 1985; 229: 547.

Swann N, Poizner H, Houser M, Gould S, Greenhouse I, Cai W, et al. Deep brain stimulation of the subthalamic nucleus alters the cortical profile of response inhibition in the beta frequency band: a scalp EEG study in Parkinson's disease. J Neurosci 2011; 31: 5721-9.

Todd NPM, Govender S, Colebatch JG. The human electrocerebellogram (ECeG) recorded noninvasively using scalp electrodes. Neurosci Lett 2018; 682: 124-31.

Toledo JB, Lopez-Azcarate J, Garcia-Garcia D, Guridi J, Valencia M, Artieda J, et al. High beta activity in the subthalamic nucleus and freezing of gait in Parkinson's disease. Neurobiol Dis 2014; 64: $60-5$.

van Dijk H, Schoffelen JM, Oostenveld R, Jensen O. Prestimulus oscillatory activity in the alpha band predicts visual discrimination ability. J Neurosci 2008; 28: 1816-23.

Walton CC, Mowszowski L, Gilat M, Hall JM, O'Callaghan C, Muller AJ, et al. Cognitive training for freezing of gait in Parkinson's disease: a randomized controlled trial. NPJ Parkinsons Dis 2018; 4: 15 .

Wan L, Huang H, Schwab N, Tanner J, Rajan A, Lam NB, et al. From eyes-closed to eyes-open: Role of cholinergic projections in EC-to-EO alpha reactivity revealed by combining EEG and MRI. Hum Brain Mapp 2019; 40: 566-77.

Wu T, Hallett M. The cerebellum in Parkinson's disease. Brain 2013; 136: 696-709.

Wu T, Liu J, Hallett M, Zheng Z, Chan P. Cerebellum and integration of neural networks in dualtask processing. NeuroImage 2013; 65: 466-75. 


\section{Figure and legends}
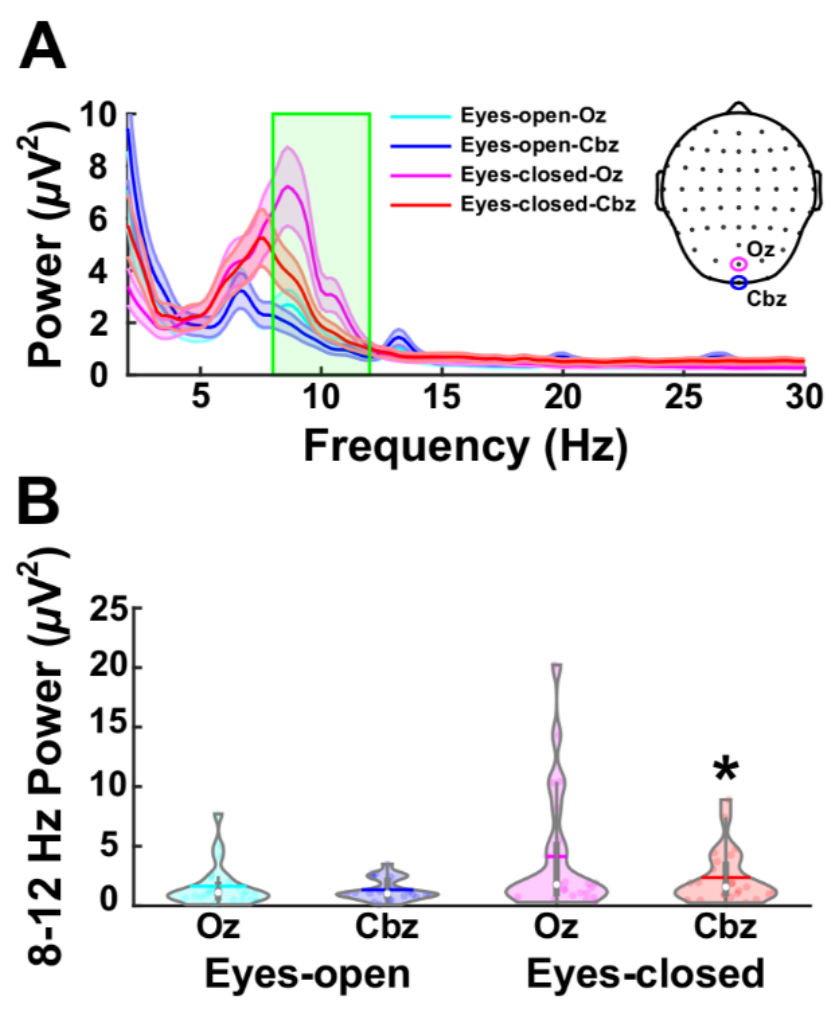

Fig. 1. Comparison between mid-cerebellar $\mathrm{Cbz}$ and mid-occipital $\mathrm{Oz}$ alpha-band oscillations during resting-state eyes-open and eyes-closed conditions in PD participants $(n=23)$. A-B) Power spectral density comparing $\mathrm{Cbz}$ and $\mathrm{Oz}$ activity during resting-state EEG shows increased alpha power $(8-12 \mathrm{~Hz}$ ) during eyes closed resting-state EEG for Oz compared to Cbz. * $\mathrm{p}<0.05$ vs. eyes closed Oz. The horizontal lines and white circles in the violin plots represent the mean and median values, respectively. 

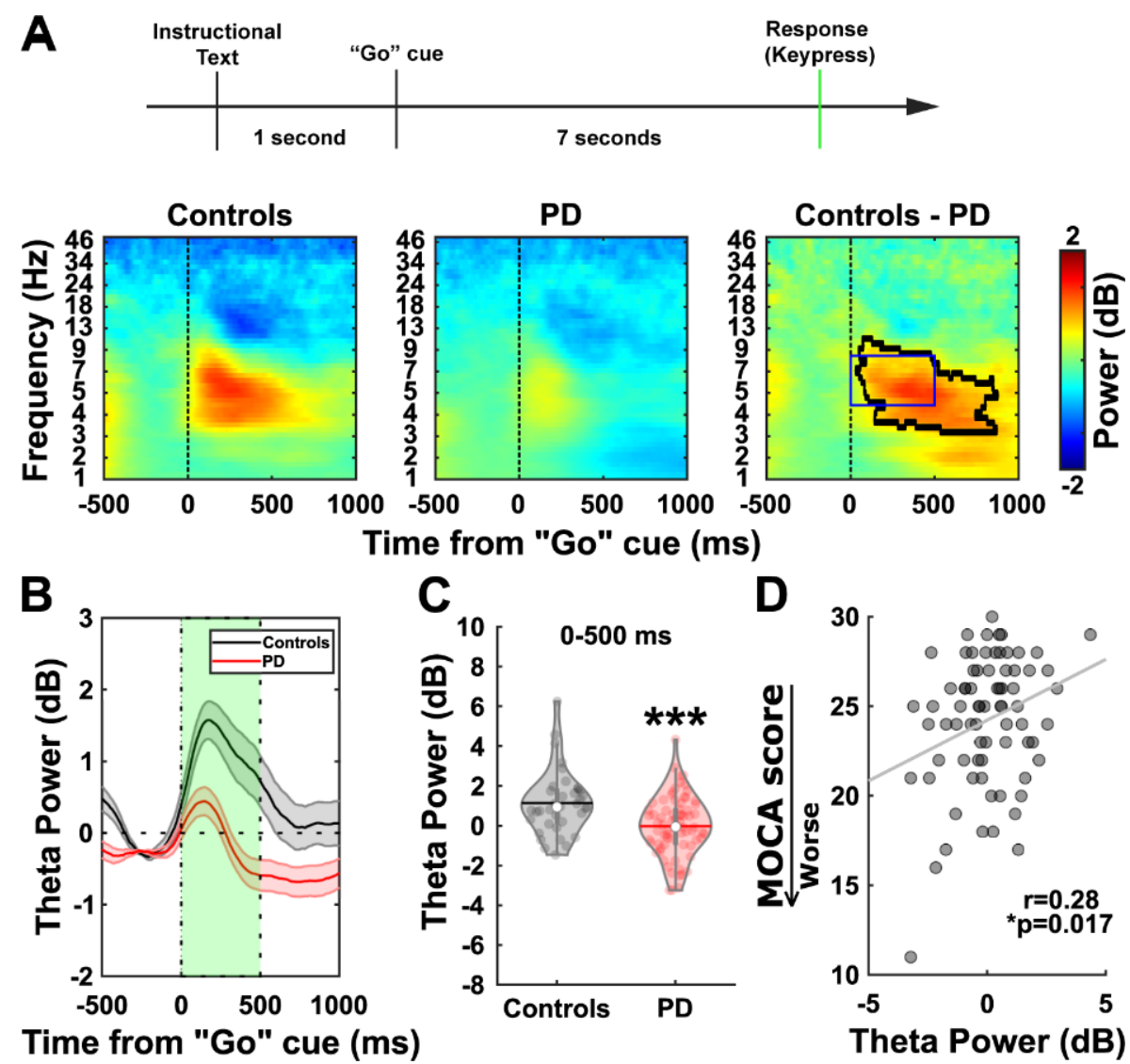

Fig. 2. Decreased mid-cerebellar Cbz theta correlates with cognitive dysfunction in PD. A) In this task, participants were shown a "Go" cue (solid box) that was displayed for 18-20 seconds. Individuals were required to indicate when they believed the target duration ( 7 seconds) had passed with a keypress (top). Time-frequency analyses comparing PD and control subjects beginning at the onset of the target "Go" cue (bottom). B) Theta power (4-7 Hz) comparison between PD and control subjects beginning at the onset of the target "Go" cue. C) Theta power is significantly decreased in PD patients (tf-ROI: blue box in A and green box in B). D) Decreased theta power associates with poor cognition as indicated by the Montreal Cognitive Assessment (MOCA) scores where lower scores indicate worse cognition. $* * * p<0.001$ vs. controls. The horizontal lines and white circles in the violin plots represent the mean and median values, respectively. 


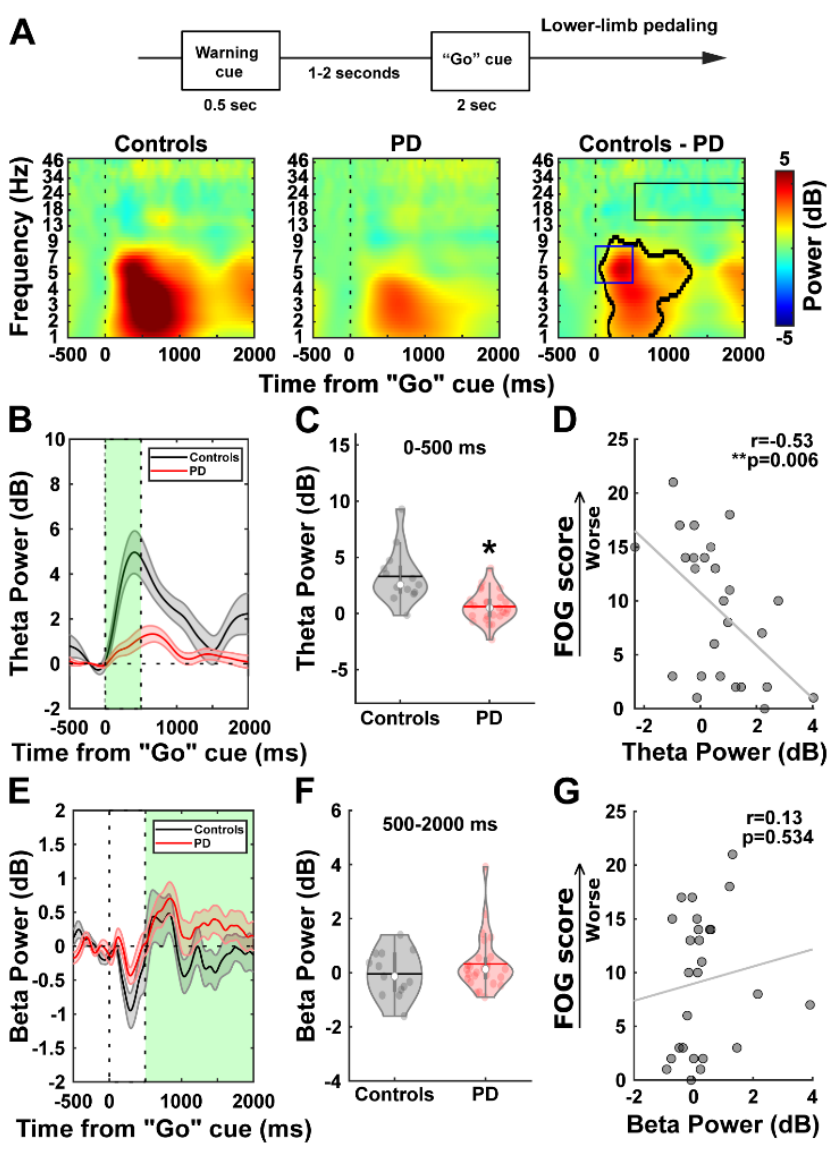

Fig. 3. Decreased mid-cerebellar Cbz theta correlates with lower-limb motor impairment in PD. A) In this task, participants were shown a "Go" cue and were required to complete one full rotation of the pedal (top). Time-frequency analyses comparing PD and control subjects beginning at the onset of the target "Go" cue (bottom). B) Theta power (4-7 Hz) comparison between PD and control subjects beginning at the onset of the target "Go" cue. C) Theta power (4-7 Hz) is significantly decreased in PD patients (tf-ROI: blue box in A and green box in B). D) Decreased theta power associates with gait impairment as indicated by freezing of gait questionnaire (FOG) scores where higher scores indicate worse gait impairment. E) Beta power (13-30 Hz) comparison between PD and control subjects after the onset of the target "Go" cue (tf-ROI: black box in A and green box in E). F) Beta power shows no significant difference in PD patients. G) Beta power is not associated with gait impairment. ${ }^{*} \mathrm{p}<0.05$ vs. controls. The horizontal lines and white circles in the violin plots represent the mean and median values, respectively. 


\section{Tables}

Table 1. Demographic details of participants

\begin{tabular}{|c|c|c|}
\hline \multicolumn{3}{|c|}{ Interval timing cognitive task } \\
\hline & 37 Controls & 74 PD patients \\
\hline Gender, M/F & $21 / 16$ & $53 / 21$ \\
\hline Age, years & $71.9(1.2)$ & $68.6(0.9)$ \\
\hline Disease Duration, years & - & $5.1(0.5)$ \\
\hline LEDD, mg & - & $849(53)$ \\
\hline $\operatorname{MOCA}(0-30)$ & $26.7(0.3)$ & $24.2(0.4)^{*}$ \\
\hline mUPDRS (0-56) & - & $13.3(0.8)$ \\
\hline \multicolumn{3}{|c|}{ Lower-limb pedaling motor task } \\
\hline & 13 Controls & 26 PD patients \\
\hline Gender, M/F & $8 / 5$ & $17 / 9$ \\
\hline Age, years & $69(2.3)$ & $67.3(1.8)$ \\
\hline Disease Duration, years & - & $6.2(0.7)$ \\
\hline LEDD, mg & - & $920.8(94.7)$ \\
\hline $\operatorname{MOCA}(0-30)$ & $26.6(0.5)$ & $23.3(0.8)^{*}$ \\
\hline mUPDRS (0-56) & - & $14.8(1.4)$ \\
\hline FOG questionnaire $(0-24)$ & - & $9.2(1.2)$ \\
\hline \multicolumn{3}{|c|}{ Resting eyes-open and closed } \\
\hline & - & 23 PD patients \\
\hline Gender, M/F & - & $17 / 6$ \\
\hline Age, years & - & $66.8(1.9)$ \\
\hline mUPDRS (0-56) & - & $16.2(1.3)$ \\
\hline \multicolumn{3}{|c|}{ EEG and EMG: Rest and Action } \\
\hline & - & 5 PD patients \\
\hline Gender, M/F & - & $3 / 2$ \\
\hline Age, years & - & $67.4(1)$ \\
\hline mUPDRS (0-56) & - & $39.8(8.2)$ \\
\hline
\end{tabular}

Values are expressed as mean (standard error of mean). Independent t-test was performed for comparison between controls vs PD patients. ${ }^{*} \mathrm{p}<0.01$. Abbreviations: Male (M); Female (F); Levodopa equivalent daily dose (LEDD); Montreal Cognitive Assessment (MOCA); motor Unified Parkinson’s Disease Rating Scale (mUPDRS); Freezing of gait (FOG). 
medRxiv preprint doi: https://doi.org/10.1101/2021.08.21.21262412; this version posted August 26, 2021. The copyright holder for this preprint (which was not certified by peer review) is the author/funder, who has granted medRxiv a license to display the preprint in perpetuity.

All rights reserved. No reuse allowed without permission.

\section{Supplementary Information}

\section{Altered cerebellar oscillations in Parkinson's disease patients during cognitive and}

\section{motor tasks}

Taylor J. Bosch, ${ }^{1,2}$ Christopher Groth, ${ }^{3}$ Tiffany A. Eldridge, ${ }^{2}$

Etienne Z. Gnimpieba, ${ }^{1,4}$ Lee A. Baugh, ${ }^{1,2}$ Arun Singh, ${ }^{1,2, *}$ 

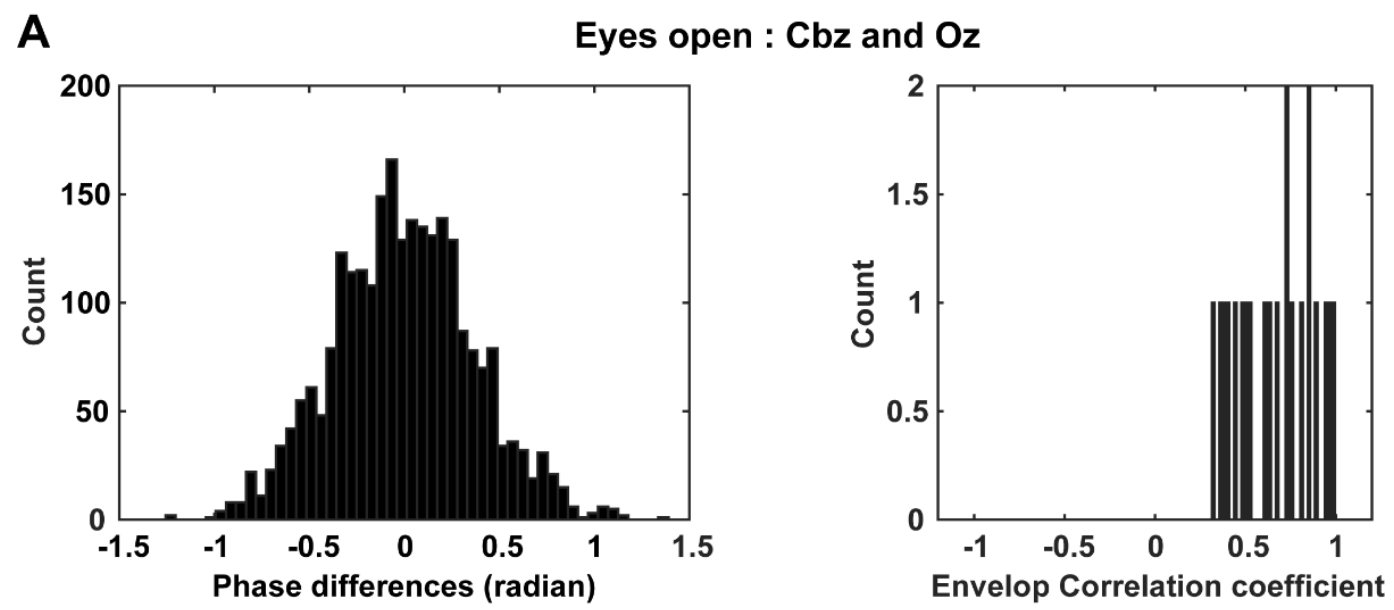

B

Eyes closed : $\mathrm{Cbz}$ and $\mathrm{Oz}$
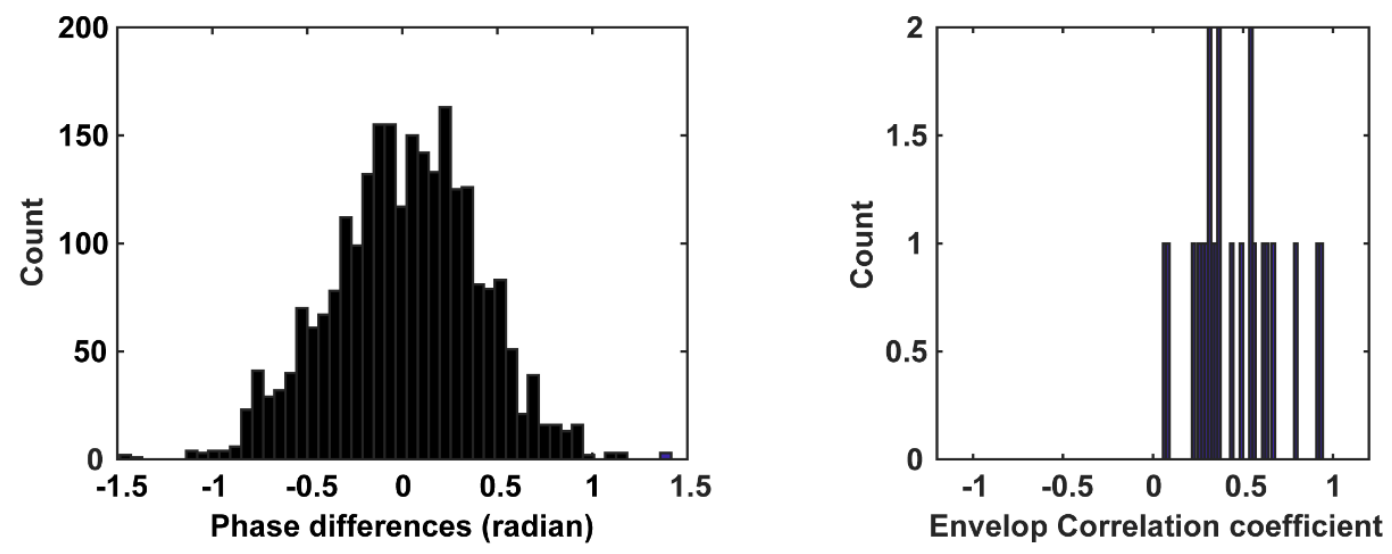

Fig. S1. Phase and envelope analyses between $\mathrm{Cbz}$ and $\mathrm{Oz}$ ( $\mathrm{n}=23$ PD subjects). A-B) Average histograms of phase angle differences and average envelope correlation coefficient across 23 PD patients with 50 bins show dispersed and greater differences in phase angle, and lower envelop correlation coefficients during the resting-state eyes-open and eyes-closed conditions. 
A

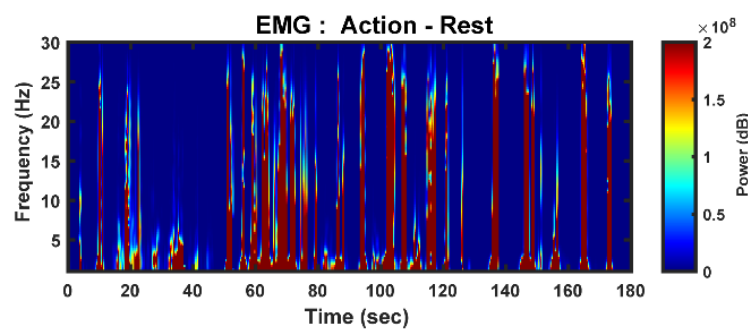

B
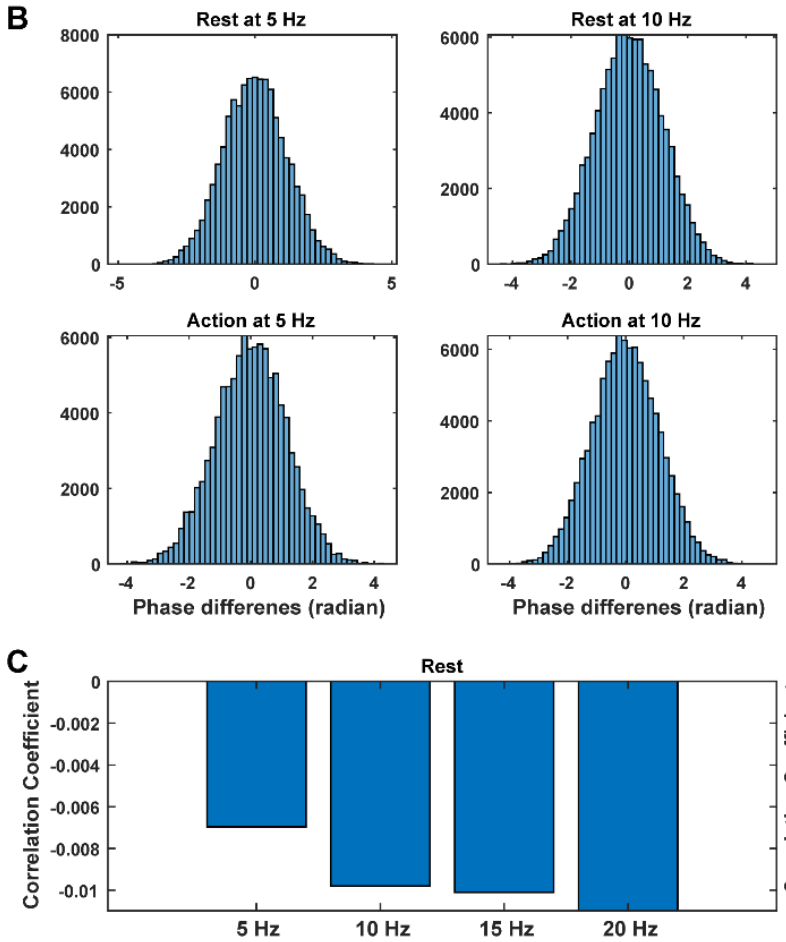

D

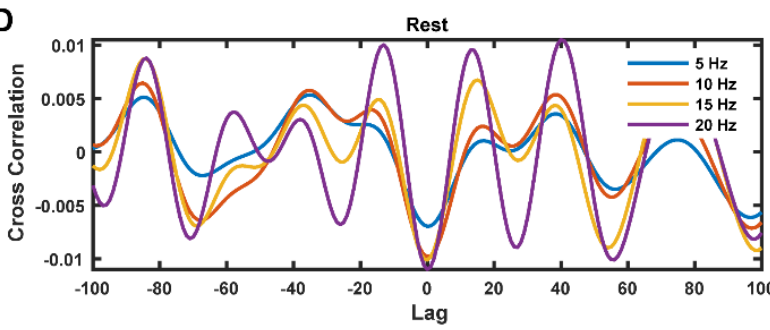

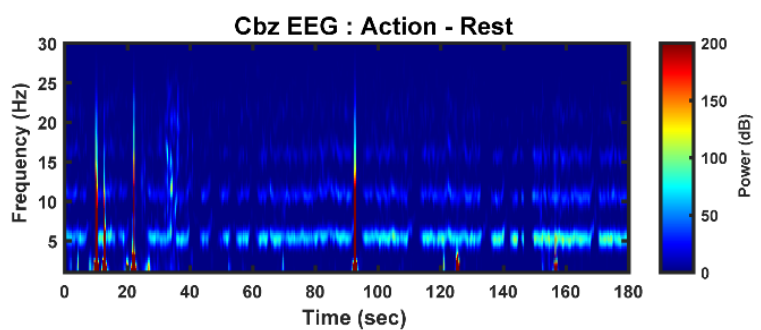
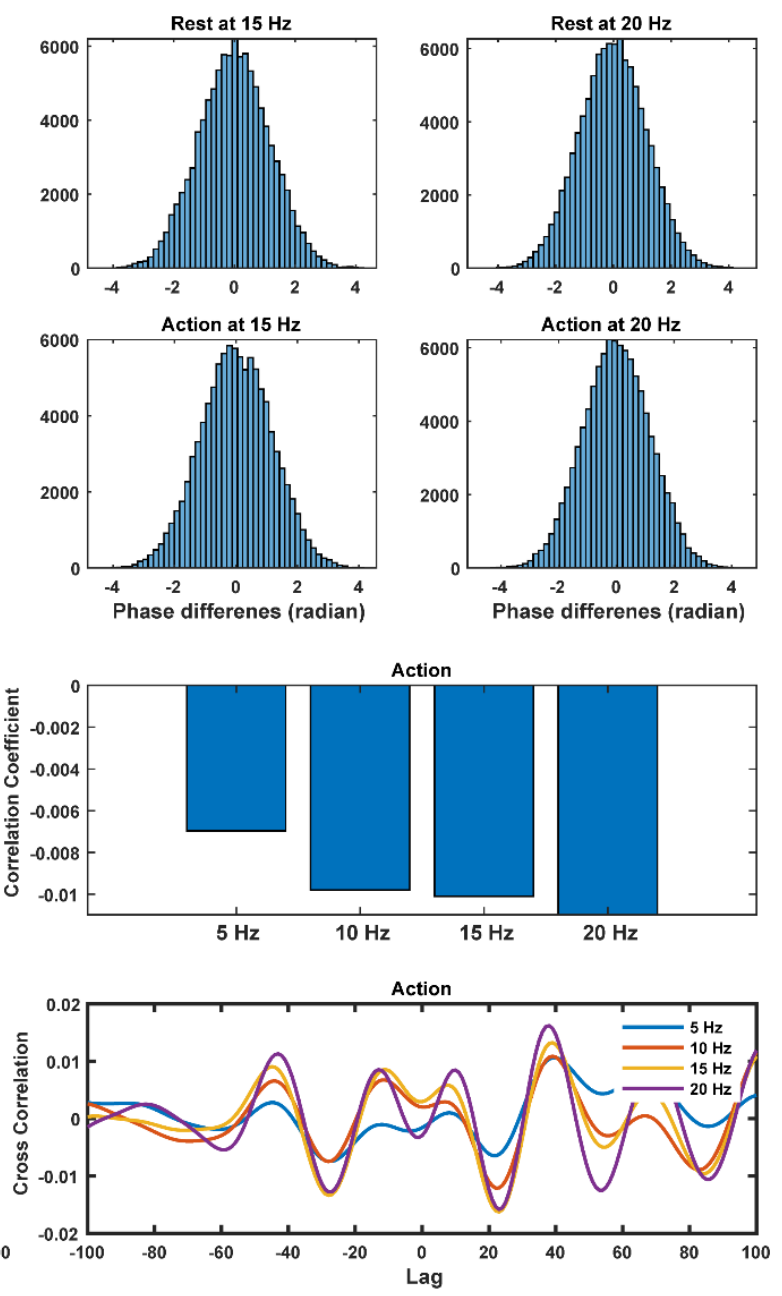

Fig. S2. Mid-cerebellar EEG and nearby EMG signals during rest and action ( $n=5$ PD subjects). A) Average time frequency differences between action and rest conditions for EMG electrodes placed over the semispinalis capitis muscle across 5 PD subjects. B) Average histograms with 50 bins at 5, 10, 15, and $20 \mathrm{~Hz}$ assessing phase differences between EMG and EEG electrodes. C) Average correlation coefficients between EEG and EMG electrodes. D) Average cross correlation analyses between EMG and EEG electrodes assessing zero-lag relationships. 
A

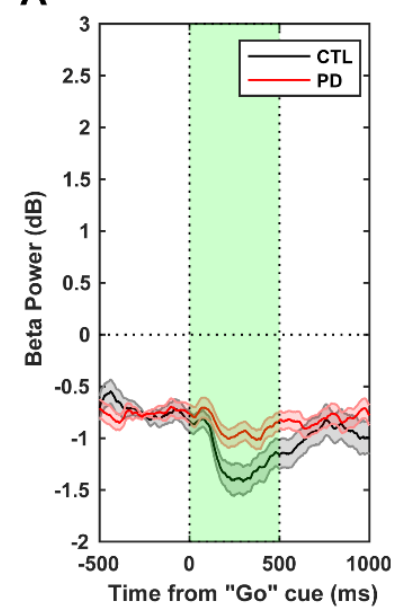

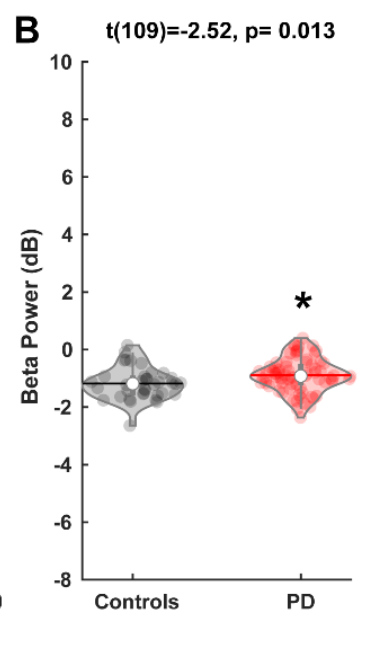
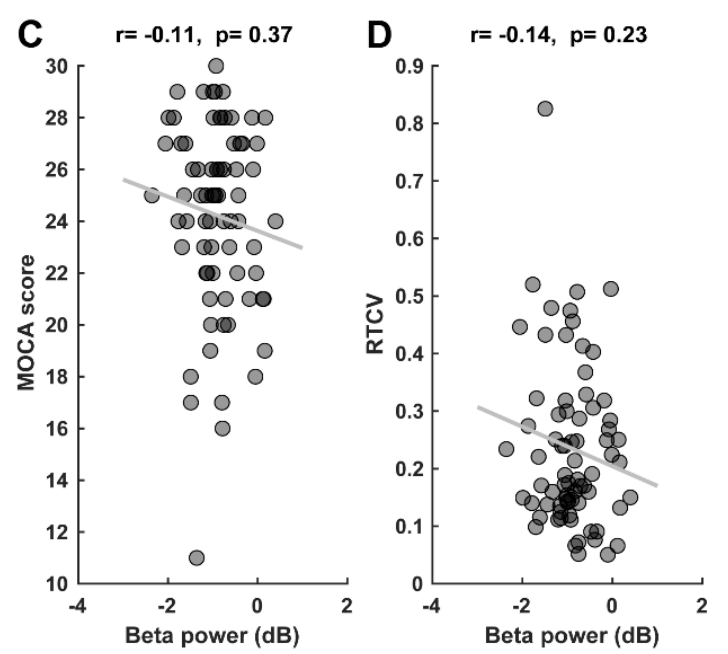

Fig. S3. Cue-triggered mid-cerebellar Cbz beta-band activity during the interval timing task. A) Beta power (13-30 Hz) comparison between PD and control subject at the onset of the target "Go" cue. B) Beta power is significantly increased in PD patients compared to controls. C-D) No relationships is observed between beta power and cognition as indicated by MOCA scores and RTCV. ${ }^{*} p<0.05$ vs. controls. The horizontal lines and white circles in the violin plots represent the mean and median values, respectively. 
A

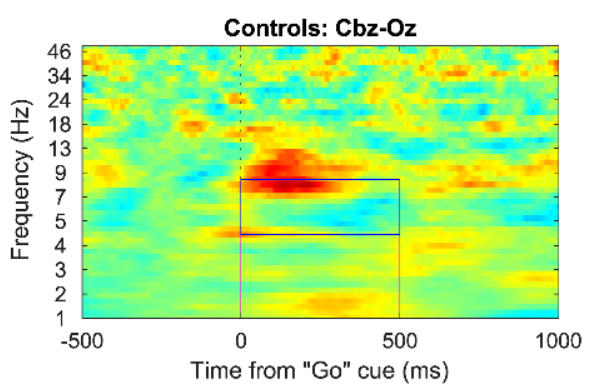

B

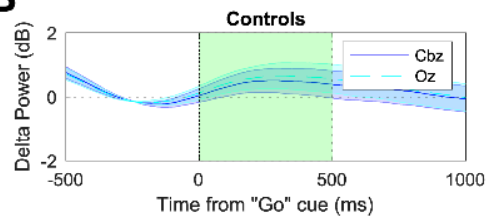

D
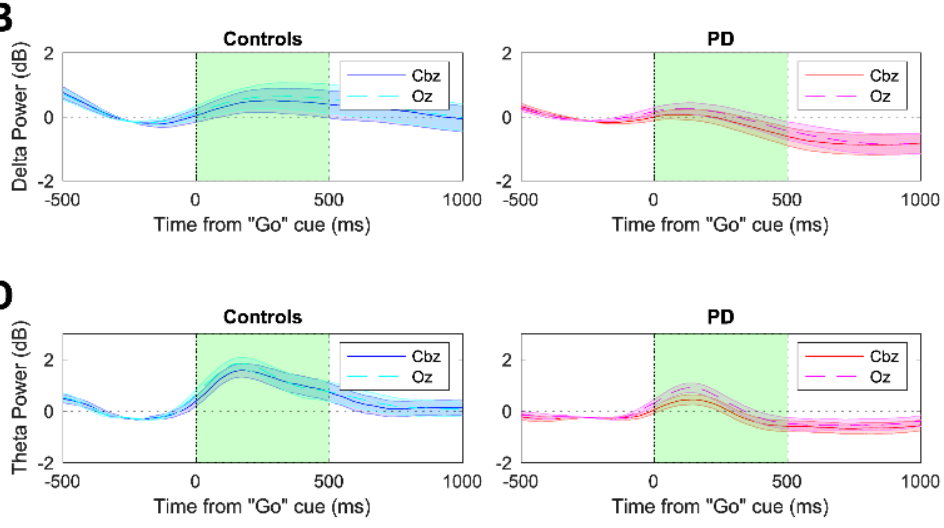

$\mathbf{F}$

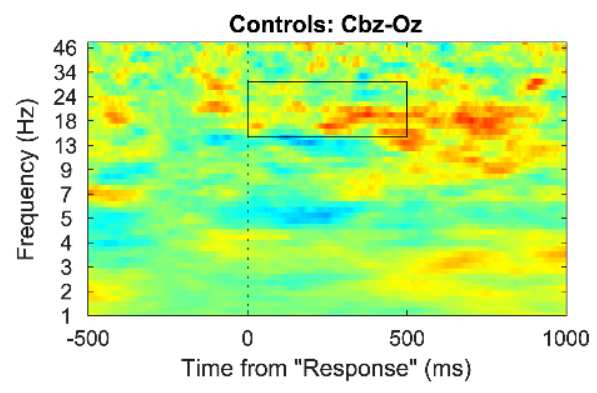

G
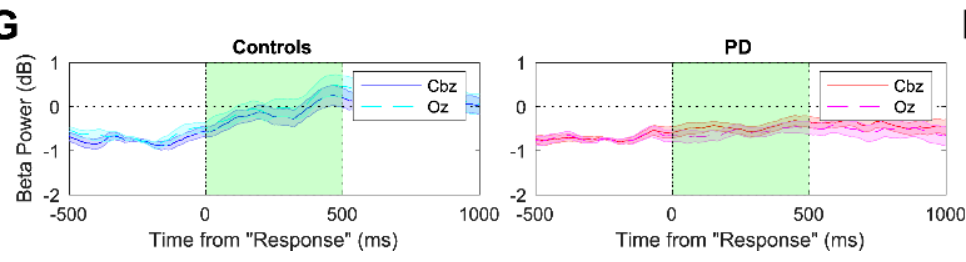

H
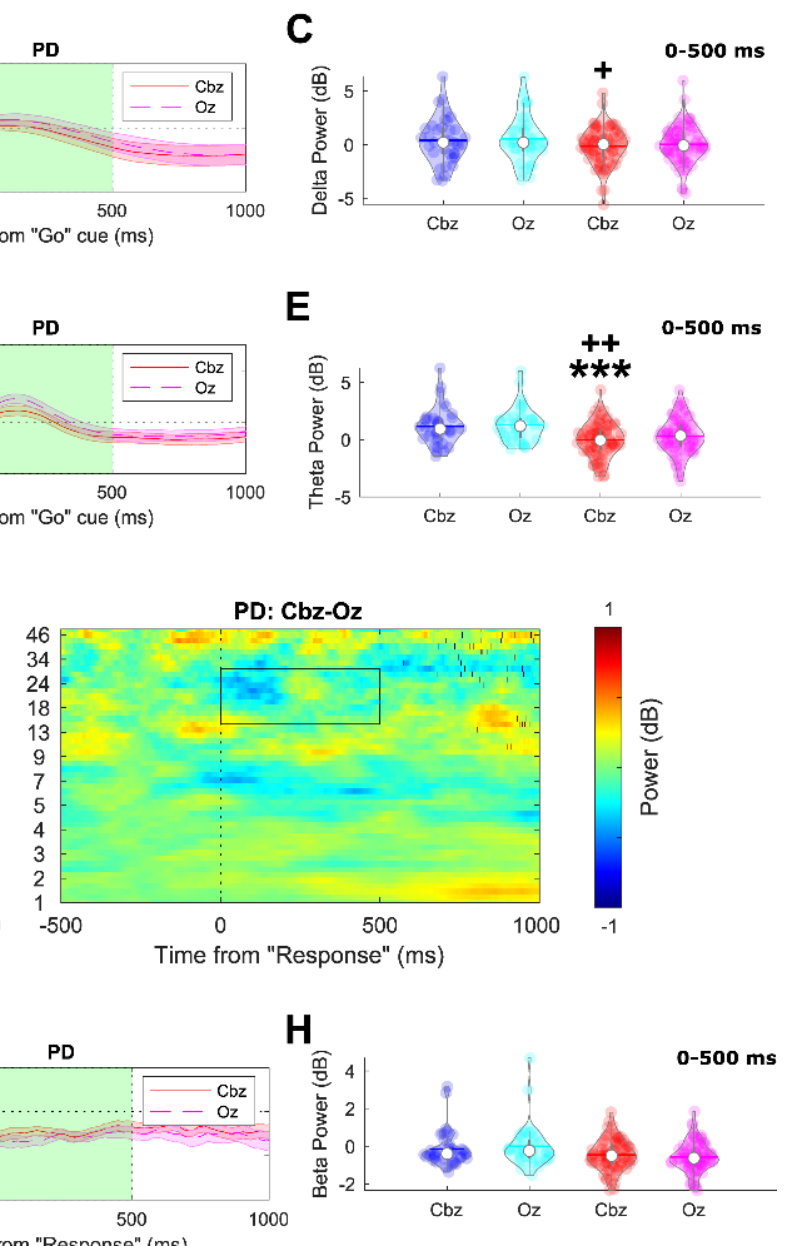

Fig. S4. Comparison between mid-cerebellar Cbz and mid-occipital Oz delta, theta, and beta power during an interval timing cognitive task. A) Time-frequency analyses comparing cue-triggered $\mathrm{Cbz}$ and $\mathrm{Oz}$ activity in PD and controls. B-C) Cue-triggered delta is decreased in PD at Cbz. D-E) Cuetriggered theta is decreased in PD at Cbz. F) Time-frequency analyses comparing responsetriggered $\mathrm{Cbz}$ and $\mathrm{Oz}$ activity in $\mathrm{PD}$ and controls. G-H) Response-triggered beta shows no difference. Please see table S1 for statistical analysis. $+p<0.05$ vs. PD-Oz; $++p<0.01$ vs. PD-Oz; $* * * p<0.001$ vs. control-Cbz. The horizontal lines and white circles in the violin plots represent the mean and median values, respectively. 

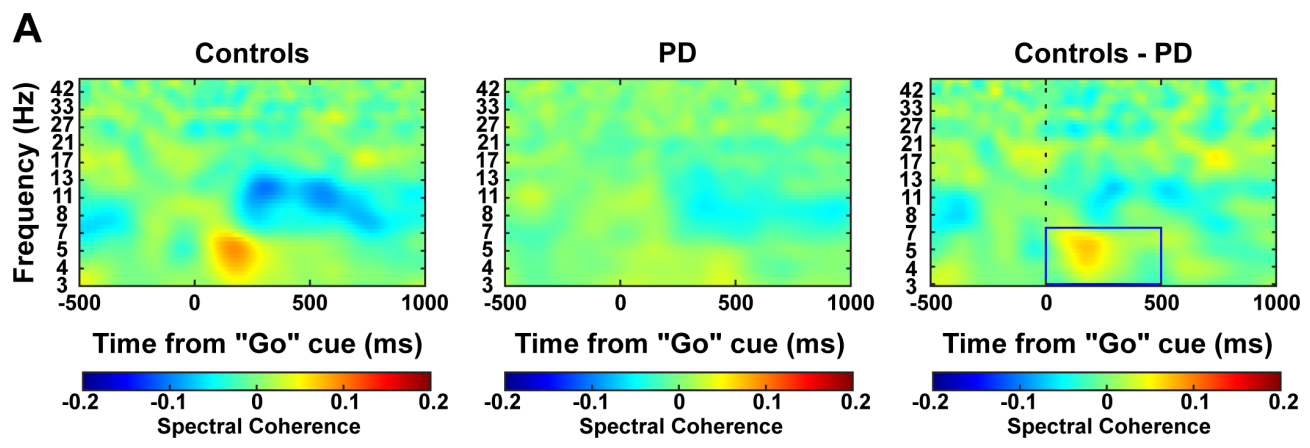

B
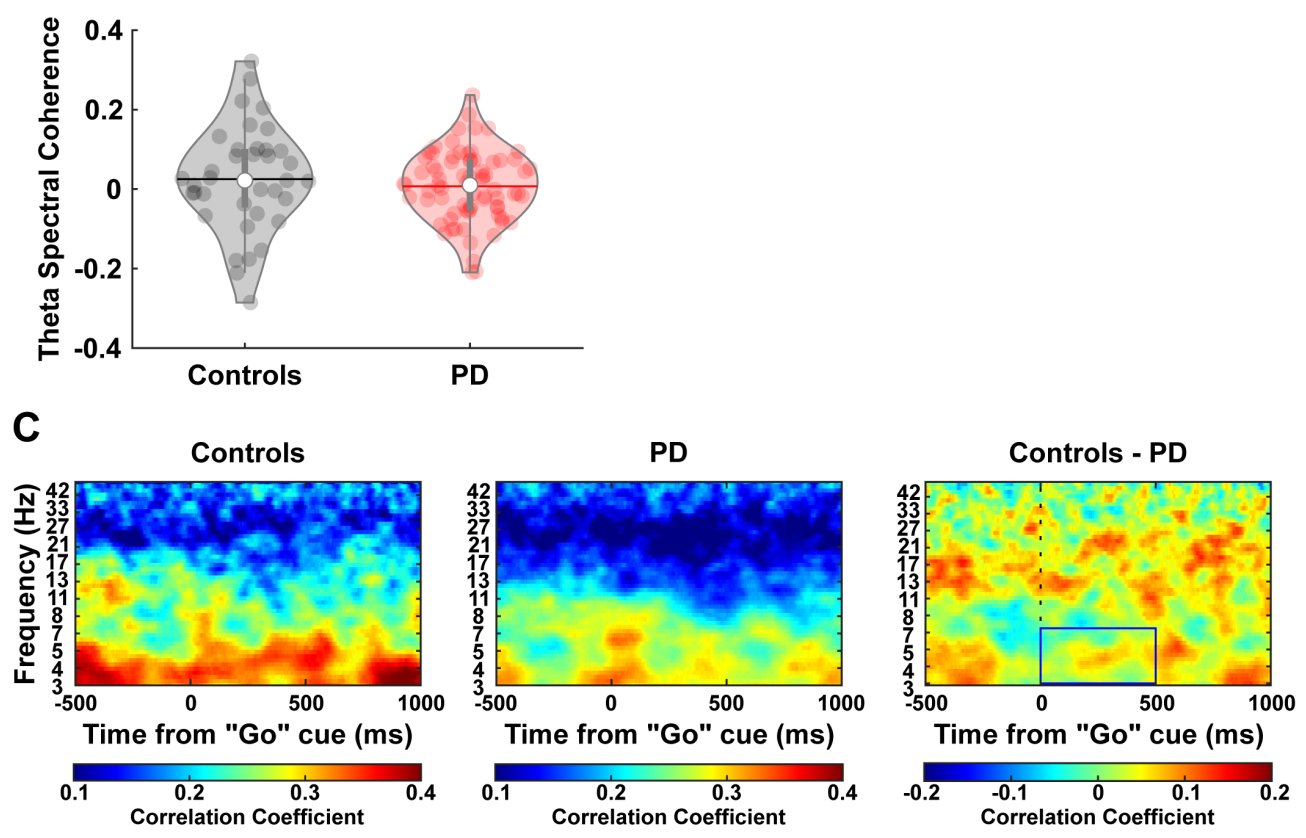

D

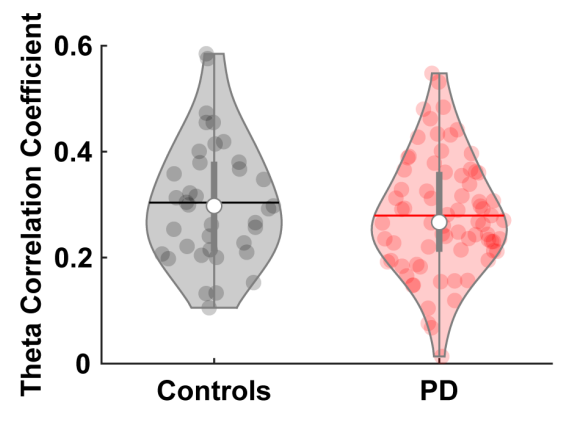

Fig. S5. Mid-cerebellar and mid-frontal connectivity analyses comparing PD patients and control subjects during an interval timing cognitive task. (A) Time-frequency analysis comparing Cbz and $\mathrm{Cz}$ spectral coherence in PD and control subjects. (B) No difference in spectral coherence is observed between PD and control subjects in the theta-band. (C) Time-frequency analysis comparing $\mathrm{Cbz}$ and $\mathrm{Cz}$ power correlation coefficients in $\mathrm{PD}$ and control subjects. (D) No difference in power correlation coefficients were observed between PD and control subjects in the theta-band. The horizontal lines and white circles in the violin plots represent the mean and median values, respectively. 
A
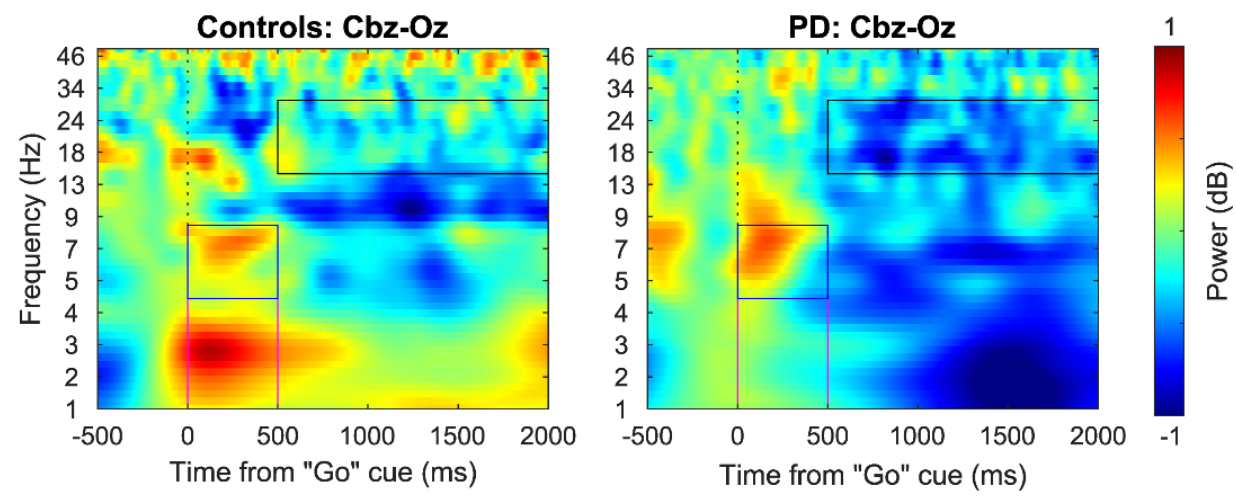

B

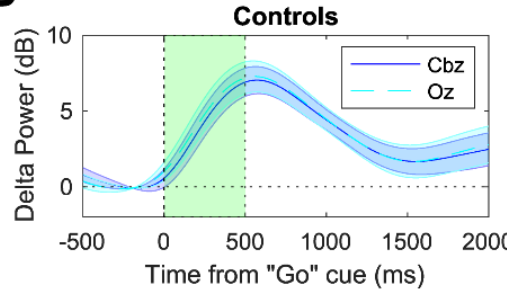

D

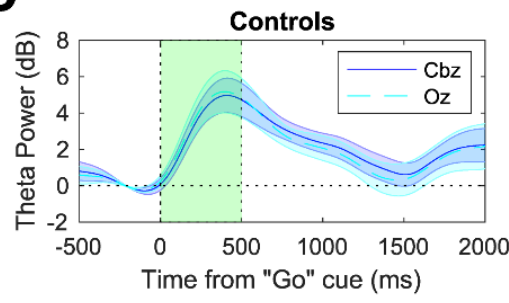

$\mathbf{F}$

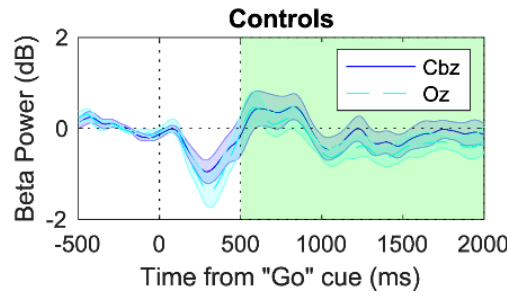

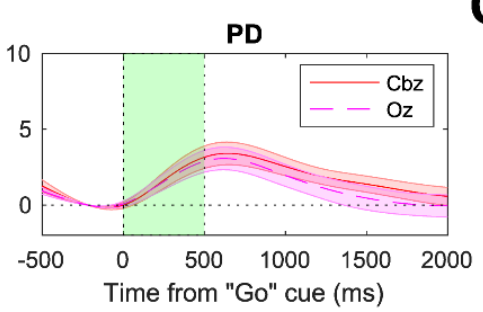

C

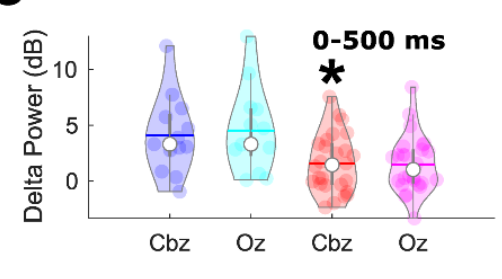

E
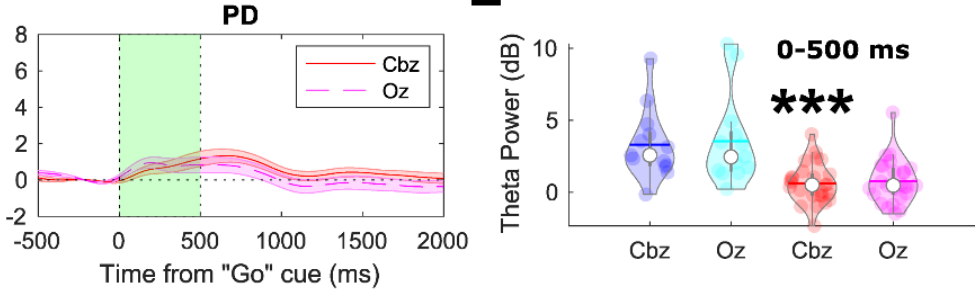

G
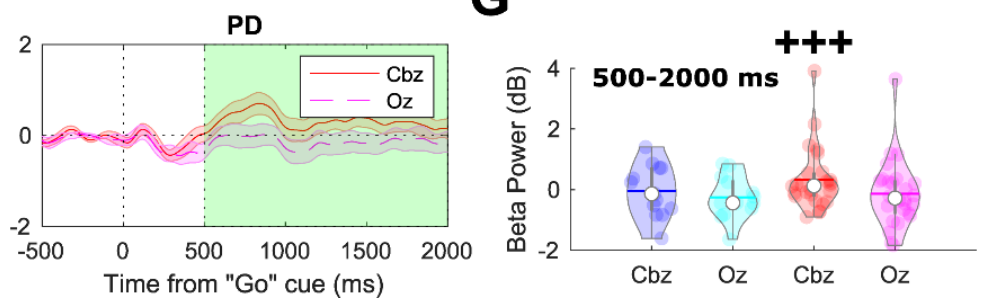

Fig. S6. Comparison between mid-cerebellar $\mathrm{Cbz}$ and mid-occipital $\mathrm{Oz}$ delta, theta, and beta power during a lower-limb pedaling motor task. A) Time-frequency analysis comparing cue-triggered $\mathrm{Cbz}$ and $\mathrm{Oz}$ activity in $\mathrm{PD}$ and controls. B-C) Cue-triggered delta power is decreased in $\mathrm{PD}$ at $\mathrm{Cbz}$. D-E) Cue-triggered theta power is decreased in PD at Cbz. F-G) Cue-triggered beta in the 500$2000 \mathrm{~ms}$ time-window is increased in PD at Cbz. Please see table $\mathrm{S} 1$ for statistical analysis. ${ }^{*}<0.05$ vs. control-Cbz; $* * *<0.001$ vs. control-Cbz; $+++\mathrm{p}<0.001$ vs. PD-Oz. The horizontal lines and white circles in the violin plots represent the mean and median values, respectively. 


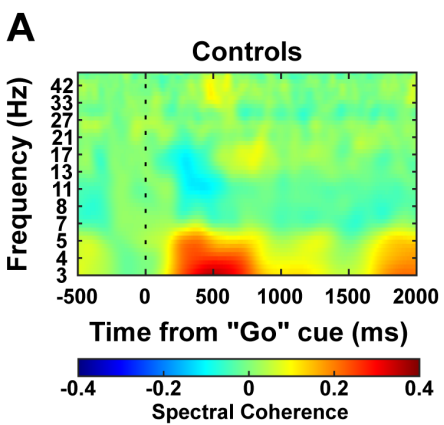

B

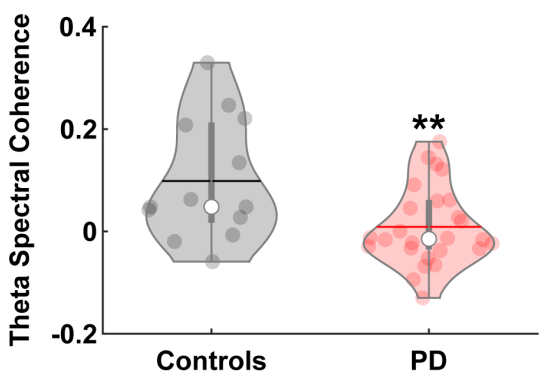

D

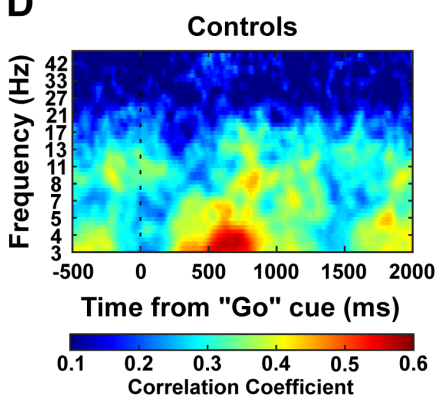

E

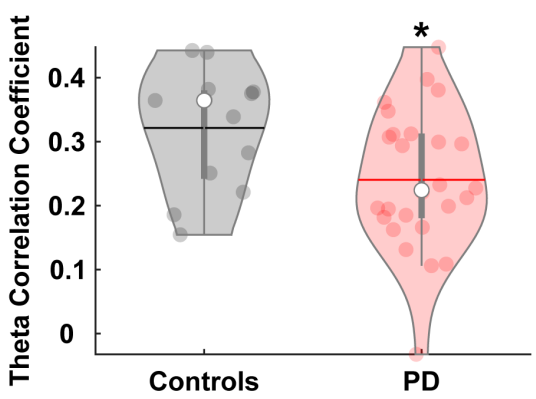

PD

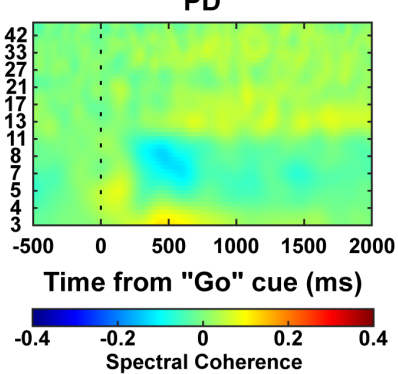

C
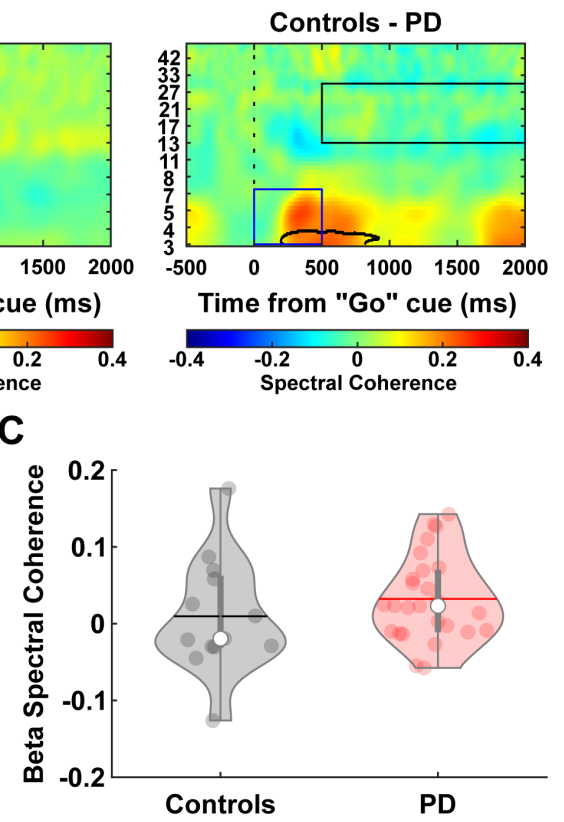

PD
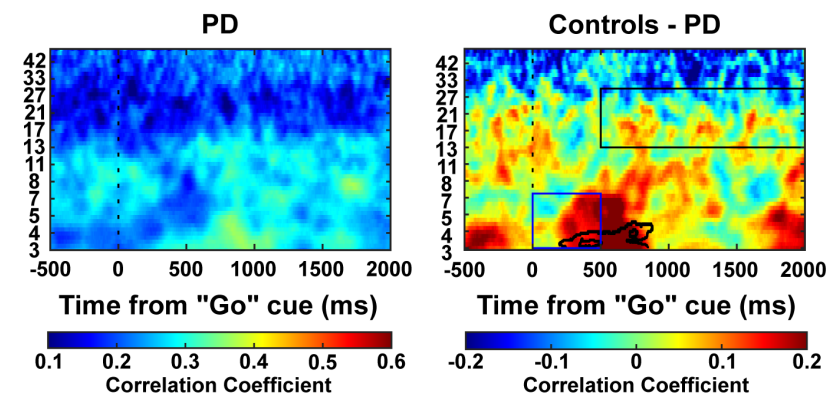

$\mathbf{F}$

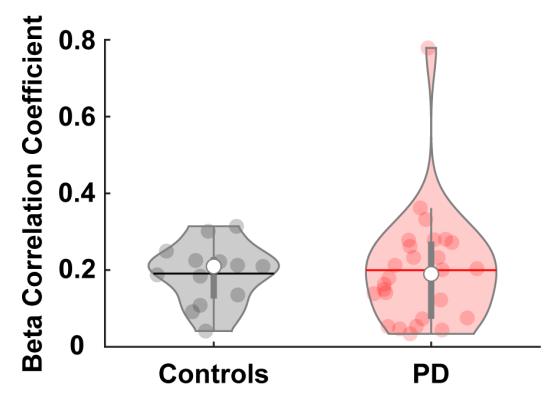

Fig. S7. Mid-cerebellar and mid-frontal connectivity analyses comparing PD patients and control subjects during a lower-limb pedaling motor task. (A) Time-frequency analysis comparing $\mathrm{Cbz}$ and $\mathrm{Cz}$ spectral coherence in PD and control subjects. (B-C) Spectral coherence between $\mathrm{Cz}$ and $\mathrm{Cbz}$ is decreased at the theta-band in PD and no difference is observed in the beta-band. (D) Timefrequency analysis comparing $\mathrm{Cbz}$ and $\mathrm{Cz}$ power correlation coefficients in $\mathrm{PD}$ and control subjects. (E-F) Correlation coefficient between $\mathrm{Cbz}$ and $\mathrm{Cz}$ is decreased at the theta-band in PD and no difference is observed in the beta-band. ${ }^{*} p<0.05$ vs. controls. ${ }^{*} p<0.01$ vs. controls. The horizontal lines and white circles in the violin plots represent the mean and median values, respectively. 

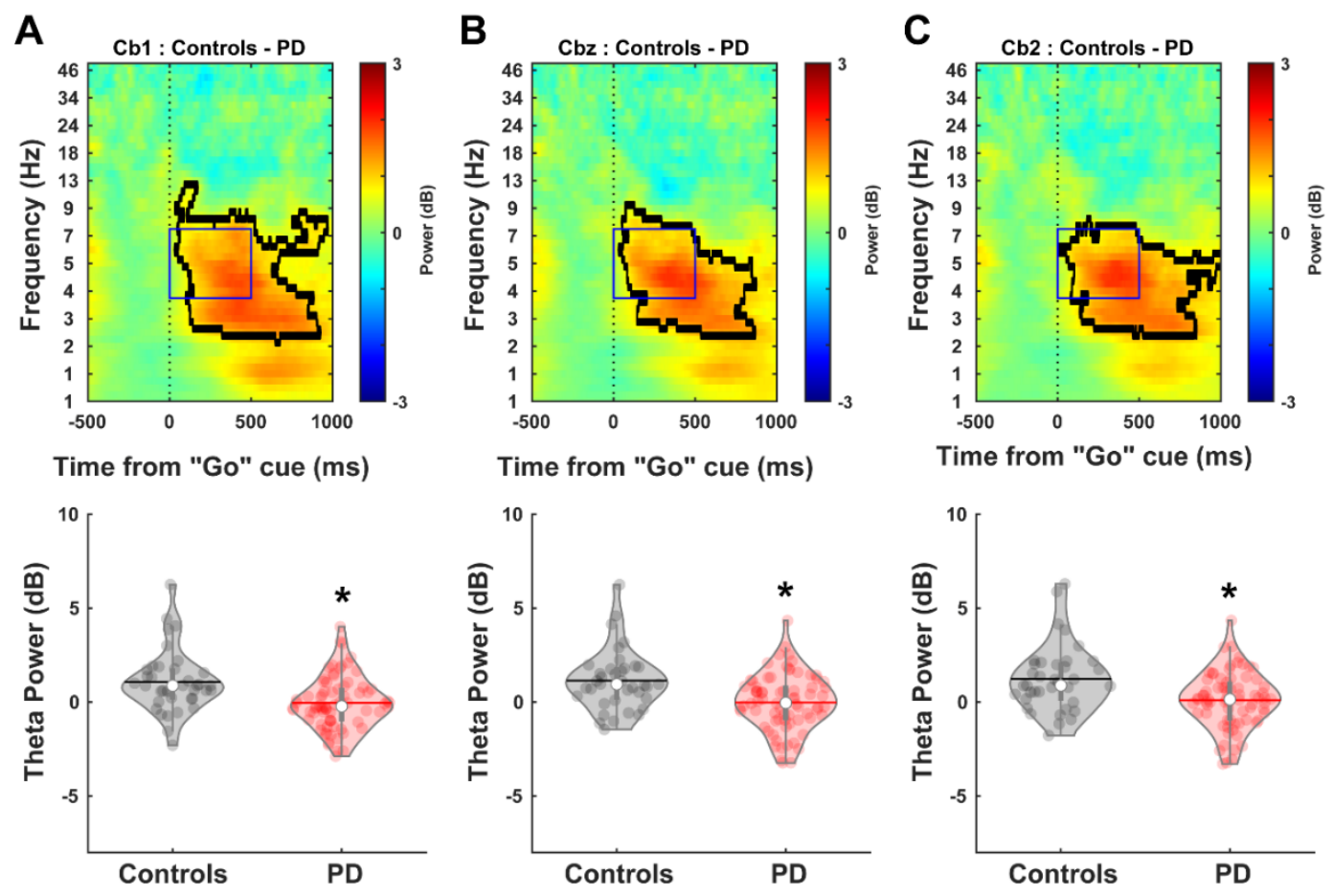

Fig. S8. Comparison between PD and control subjects during the interval timing cognitive task at lateral cerebellar (left $\mathrm{Cb} 1$ and right $\mathrm{Cb} 2$ ) and mid-cerebellar $\mathrm{Cbz}$ locations. Time-frequency analyses show attenuated theta-band power in PD patients at A) left lateral $\mathrm{Cb} 1, \mathrm{~B}$ ) mid-cerebellar $\mathrm{Cbz}$, and $\mathrm{C}$ ) right lateral $\mathrm{Cb} 2 . * 0.01$ vs. controls. The horizontal lines and white circles in the violin plots represent the mean and median values, respectively. 

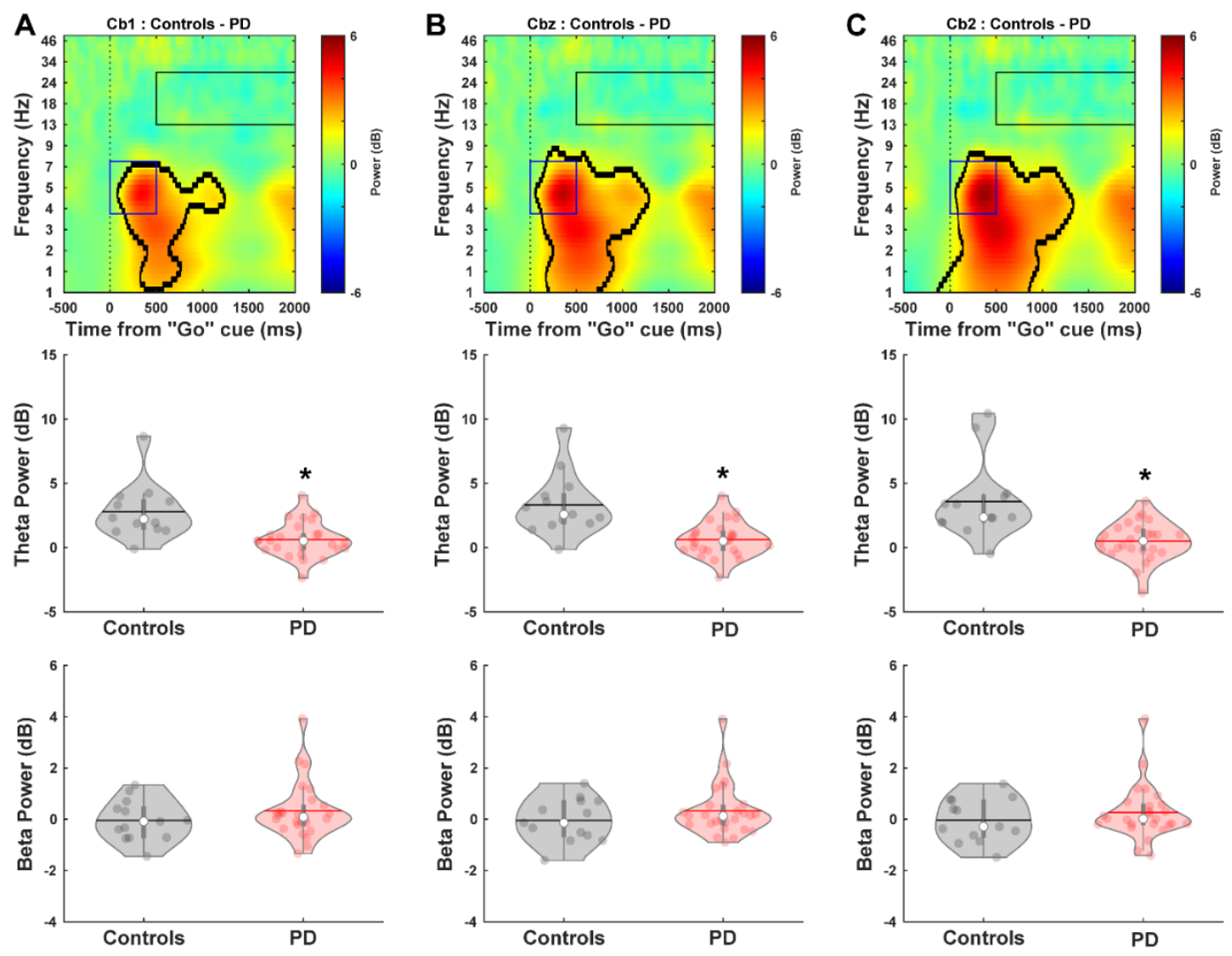

Fig. S9. Comparison between PD and control subjects during the lower-limb pedaling motor task at lateral cerebellar (left $\mathrm{Cb} 1$ and right $\mathrm{Cb} 2$ ) and mid-cerebellar $\mathrm{Cbz}$ locations. Middle row: timefrequency analyses show attenuated theta-band power in PD patients A) left lateral Cb1, B) midcerebellar $\mathrm{Cbz}$, and $\mathrm{C}$ ) right lateral $\mathrm{Cb} 2$. Bottom row: no differences are observed in the beta-band. $*<0.01$ vs. controls. The horizontal lines and white circles in the violin plots represent the mean and median values, respectively. 
Table S1. Summary of repeated measure ANOVA tests for tf-ROIs during interval timing cognitive and lower-limb pedaling motor tasks.

Group

(Controls and PD patients)
Electrode

(Cbz and Oz)
Pairwise

Group*Electrode comparisons:

(Controls vs. PD)
Pairwise comparisons:

(Cbz vs. Oz)

\section{Interval timing cognitive task}

\begin{tabular}{|c|c|c|c|c|c|}
\hline Delta-band & $\begin{array}{l}F(1,109)=1.97 \\
p=0.16\end{array}$ & $\begin{array}{l}F(1,109)=6.83 \\
p=0.01 *\end{array}$ & $\begin{array}{l}F(1,109)=0.15 \\
p=0.7\end{array}$ & $\begin{array}{l}\text { Cbz p }=0.15 \\
\mathrm{Oz} \mathrm{p}=0.2\end{array}$ & $\begin{array}{l}\text { CTL } p=0.15 \\
\text { PD p }=0.033^{*}\end{array}$ \\
\hline Theta-band & $\begin{array}{l}\mathrm{F}(1,109)=13.2 \\
\mathrm{p}=0.0004 * * *\end{array}$ & $\begin{array}{l}F(1,109)=8.6 \\
p=0.004 * *\end{array}$ & $\begin{array}{l}F(1,109)=0.89 \\
p=0.35\end{array}$ & $\begin{array}{l}\text { Cbz } \mathrm{p}<0.0001^{* * *} \\
\text { Oz p }=0.002 * *\end{array}$ & $\begin{array}{l}\text { CTL } p=0.39 \\
\text { PD } p=0.003^{* *}\end{array}$ \\
\hline Beta-band & $\begin{array}{l}F(1,109)=6.65 \\
p=0.01 *\end{array}$ & $\begin{array}{l}F(1,109)=0.35 \\
p=0.55\end{array}$ & $\begin{array}{l}F(1,109)=6.7 \\
p=0.01 *\end{array}$ & $\begin{array}{l}\text { Cbz p }=0.07 \\
\text { Oz p }=0.003 * *\end{array}$ & $\begin{array}{l}\text { CTL } p=0.068 \\
\text { PD } p=0.058\end{array}$ \\
\hline
\end{tabular}

\section{Lower-limb pedaling motor task}

\begin{tabular}{llllll}
\hline Delta-band & $\begin{array}{l}\mathrm{F}(1,37)=8.1 \\
\mathrm{p}=0.007^{* *}\end{array}$ & $\begin{array}{l}\mathrm{F}(1,37)=0.17 \\
\mathrm{p}=0.68\end{array}$ & $\begin{array}{l}\mathrm{F}(1,37)=1.35 \\
\mathrm{p}=0.25\end{array}$ & $\begin{array}{l}\mathrm{Cbz} \mathrm{p}=0.016^{*} \\
\mathrm{Oz} \mathrm{p}=0.005^{*}\end{array}$ & $\begin{array}{l}\mathrm{CTL} \mathrm{p}=0.045^{*} \\
\mathrm{PD} \mathrm{p}=0.77\end{array}$ \\
\hline Theta-band & $\begin{array}{l}\mathrm{F}(1,37)=17.4 \\
\mathrm{p}=0.0002^{* * *}\end{array}$ & $\begin{array}{l}\mathrm{F}(1,37)=1.5 \\
\mathrm{p}=0.22\end{array}$ & $\begin{array}{l}\mathrm{F}(1,37)=0.11 \\
\mathrm{p}=0.74\end{array}$ & $\begin{array}{l}\mathrm{Cbz} \mathrm{p}<0.0001^{* * *} \\
\mathrm{Oz} \mathrm{p}=0.001^{* *}\end{array}$ & $\begin{array}{l}\mathrm{CTL} \mathrm{p}=0.48 \\
\mathrm{PD} \mathrm{p}=0.3\end{array}$ \\
\hline Beta-band & $\mathrm{F}(1,37)=0.59$ & $\mathrm{~F}(1,37)=17.1$ & $\mathrm{~F}(1,37)=1.64$ & $\mathrm{Cbz} \mathrm{p}=0.27$, & $\mathrm{CTL} \mathrm{p}=0.22$ \\
& $\mathrm{p}=0.45$ & $\mathrm{p}=0.0002^{* * *}$ & $\mathrm{p}=0.21$ & $\mathrm{Oz} \mathrm{p}=0.72$ & $\mathrm{PD}<<0.0001^{* * *}$ \\
\hline
\end{tabular}

$* * * \mathrm{p}<0.001, * * \mathrm{p}<0.01, * \mathrm{p}<0.05$. 
medRxiv preprint doi: https://doi.org/10.1101/2021.08.21.21262412; this version posted August 26, 2021. The copyright holder for this preprint (which was not certified by peer review) is the author/funder, who has granted medRxiv a license to display the preprint in perpetuity.

All rights reserved. No reuse allowed without permission.

Table S2. Mean \pm standard error of mean for cerebellar electrodes

\begin{tabular}{|c|c|c|c|}
\hline & Cb1 electrode & Cbz electrode & Cb2 electrode \\
\hline \multicolumn{4}{|c|}{ Interval Timing Cognitive Task } \\
\hline \multicolumn{4}{|c|}{ Theta Band } \\
\hline $\begin{array}{l}\text { PD } \\
\text { Controls }\end{array}$ & $\begin{array}{c}-0.05 \pm 0.16 \\
1.08 \pm 0.27\end{array}$ & $\begin{array}{r}-0.01 \pm 0.17 \\
1.15 \pm 0.26\end{array}$ & $\begin{array}{c}0.1 \pm 0.17 \\
1.24 \pm 0.29\end{array}$ \\
\hline \multicolumn{4}{|c|}{ Lower-Limb Pedaling Motor Task } \\
\hline \multicolumn{4}{|c|}{ Theta Band } \\
\hline $\begin{array}{l}\text { PD } \\
\text { Controls }\end{array}$ & $\begin{array}{c}0.63 \pm 0.27 \\
2.77 \pm 0.6\end{array}$ & $\begin{array}{l}0.62 \pm 0.27 \\
3.31 \pm 0.67\end{array}$ & $\begin{array}{c}0.5 \pm 0.3 \\
3.58 \pm 0.85\end{array}$ \\
\hline \multicolumn{4}{|c|}{ Beta Band } \\
\hline $\begin{array}{l}\text { PD } \\
\text { Controls }\end{array}$ & $\begin{array}{c}0.32 \pm 0.22 \\
-0.05 \pm 0.22\end{array}$ & $\begin{array}{c}0.32 \pm 0.2 \\
-0.04 \pm 0.24\end{array}$ & $\begin{array}{c}0.26 \pm 0.21 \\
-0.04 \pm 0.24\end{array}$ \\
\hline
\end{tabular}


Table S3. Summary of repeated measure ANOVA tests (Cb1, Cbz, and Cb2 electrodes/ controls, PD groups) for tf-ROIs during interval timing cognitive and lower-limb pedaling motor tasks.

\begin{tabular}{|c|c|c|c|c|c|}
\hline & $\begin{array}{c}\text { Sum of } \\
\text { Squares }\end{array}$ & df & $\begin{array}{c}\text { Mean } \\
\text { Square }\end{array}$ & $\mathbf{F}$ & p-value \\
\hline \multicolumn{6}{|c|}{ Interval Timing Cognitive Task } \\
\hline \multicolumn{6}{|l|}{ Theta Band } \\
\hline Electrode & 1.38 & 2 & 0.69 & 4.96 & $0.008 * *$ \\
\hline Group & 33.28 & 1 & 33.28 & 3.98 & $0.049 *$ \\
\hline Interaction & 0.003 & 2 & 0.001 & 0.01 & 0.99 \\
\hline \multicolumn{6}{|c|}{ Lower-Limb Pedaling Motor Task } \\
\hline \multicolumn{6}{|l|}{ Theta Band } \\
\hline Electrode & 6.03 & 2 & 3.02 & 4.37 & $0.02 *$ \\
\hline Group & 23 & 1 & 23 & 1.51 & 0.23 \\
\hline Interaction & 0.69 & 2 & 0.35 & 0.5 & 0.61 \\
\hline \multicolumn{6}{|c|}{ Lower-Limb Pedaling Motor Task } \\
\hline \multicolumn{6}{|l|}{ Beta Band } \\
\hline Electrode & 0.13 & 2 & 0.06 & 0.89 & 0.41 \\
\hline Group & 1.22 & 1 & 1.22 & 0.38 & 0.54 \\
\hline Interaction & 0.08 & 2 & 0.04 & 0.54 & 0.58 \\
\hline
\end{tabular}

rmANOVA with Group (PD, Controls) as the between subjects variable and Electrode (Cb1, $\mathrm{Cbz}$, and $\mathrm{Cb} 2)$ as the within subjects variable. ${ }^{*} \mathrm{p}<0.05 ; * * \mathrm{p}<0.01$. 